\title{
Lifecycle Consumption Under Different Income Profiles: Experimental Evidence*
}

\author{
John Duffy ${ }^{\dagger} \quad$ Yue $\mathrm{Li}^{\ddagger}$
}

October 17, 2016

\begin{abstract}
We report on a series of economic decision-making experiments exploring how individuals make lifecycle consumption and saving plans when they face different income profiles. We find that for every income profile we consider, subjects on average overconsume in the early periods of life and under-consume in later periods of life relative to the conditional optimum and any sudden drop in income reduces their lifetime utility. We conduct a specification search for a model to explain our data and find that a two-type model with one type consuming the conditional optimum and the other type consuming endowments best fits our data.
\end{abstract}

Keywords: Lifecycle model, consumption and savings, retirement planning, behavioral and experimental economics.

JEL Codes: C91, D91, E21, H55.

${ }^{*}$ We would like to thank seminar participants at SUNY Albany, and the Barcelona Summer Graduate Forum for valuable comments and suggestions. We gratefully acknowledge funding for this project from the UC Irvine School of Social Sciences. The experimental protocol was approved by UC Irvine's Institutional Review Board, HS\#2015-2082

$\dagger$ Department of Economics, University of California, Irvine. Email: duffy@uci.edu.

${ }_{\ddagger}^{\ddagger}$ Department of Economics, University of Albany, SUNY, Email: yli49@albany.edu. 


\section{Introduction}

The Social Security Act was signed into law by President Roosevelt on August 14, 1935. Over the program's 80-year history, it has collected roughly $\$ 19$ trillion in revenue and paid out $\$ 16$ trillion in benefits. Despite the $\$ 2.8$ trillion reserve held at the end of year 2015 , the social security trust fund is expected to be depleted in 2035 (Social Security Administration, 2016). To resolve this long-term solvency issue, major changes in the social security program are anticipated. One potential change is in the social security replacement rate-the rate of social security benefits to pre-retirement after-tax average earnings. The purpose of this paper is to use experimental methods to begin the process of understanding how variations in social security replacement rates might aid or hinder individuals' ability to make good lifecycle consumption and savings plans, an assessment that is difficult to conduct in the field.

We study environments where subjects are induced to hold concave preferences over consumption in each of the 25 periods of their lifetimes so that lifecycle consumption smoothing is desirable according to the standard rational actor approach. Within this environment, we consider how subjects make consumption and savings decisions facing several different lifecycle profiles for their income. These lifecycle income processes are known with certainty, and some of them involve explicit drops in income to mimic a retirement phase of life. To allow subjects to learn, we have them participate in two 25-period lifetimes (sequences) under the same lifecycle income process.

Our assumption that the lifecycle income process is deterministic and known in advance is clearly an idealized, best-case-scenario, but it provides us with an important benchmark for more rigorous analysis; if subjects are unable to intertemporally smooth their consumption and save for retirement in this very simple environment, then such difficulties are likely to be further compounded in settings with uncertain and highly variable income processes. A 
further rationale for studying lifecycle consumption and savings plans under a deterministic income process is that it is possible to analytically solve for the optimal consumption path, given the induced concave utility function. ${ }^{1}$

Our main aim in designing these experiments and analyzing the results is to first understand the extent to which the rational choice theory is relevant to our subject's decisionmaking. To preview our results, we find that subjects exhibit large and economically significant departures from rational choice theory predictions. Under all lifecycle income profiles we consider, subjects display excess sensitivity to current income and they over-consume in the early periods of the lifecycle and under-consume in later periods relative to both the unconditionally and the conditionally optimal paths. On the other hand, we also find evidence that subjects improve their performance in the direction of the optimal path with repeated experience under the same endowment (income) profile and that the particular lifecycle endowment profile matters for how close subjects get to the unconditionally or conditionally optimal path. In particular, for the first lifecycle sequence, subjects assigned to the treatment with a constant endowment profile over the lifecycle deviate less from the unconditionally optimal path and have greater lifetime utility than subjects assigned to our other three treatments involving a sudden drop in endowment income.

Our second aim is to propose and empirically validate an alternative behavioral model of consumption that can better explain subjects' behavior in this standard lifecycle framework. The development of such an alternative, behavioral model of lifecycle consumption and savings decisions, validated by experimental data, is a necessary first step for evaluating the role of various policy changes on consumption behavior. By comparing the root mean squared deviation (RMSD) between the data and the predictions of various alternative models, we find that a two-type model, consisting of one type consuming the conditionally optimal

\footnotetext{
${ }^{1}$ As Carroll (2001) notes "when there is uncertainty about the future level of labor income, it appears to be impossible under plausible assumptions about the utility function to derive an explicit solution for consumption as a direct (analytical) function of the model's parameters." To better evaluate our subjects' performance we wish to study environments where the solution to the planning problem can be computed.
} 
level of consumption and the other type consuming their period-by-period endowment - a variation of the model proposed by Campbell and Mankiw (1989) and Mankiw (2000) - is the one that best fits our experimental data.

Finally, regarding policy implications, we find that a social security policy providing partial or complete replacement of non-capital income upon retirement provides welfare gains for some individuals who lack the foresight to save adequately. As Diamond (1977) notes the "justification for social security is that many individuals will not save enough for retirement if left to their own devices". ${ }^{2}$ Our results provide supportive evidence for this statement- - for some individuals who behave like hand-to-mouth consumers, a more generous social security retirement benefit funded by greater taxes during their working age is welfare improving. At the same time, the number of individuals who choose the conditionally optimal path, depends on the social security replacement rate. Using our experimental data, we find that the share of subjects classified as making conditionally optimal consumption choices is the smallest in our treatment with a constant income over the lifecycle, which is achieved by having a 100 percent social security replacement rate.

This paper complements four strands of existing research. The first strand uses laboratory experiments to study consumption and saving decisions over a finite lifetime. ${ }^{3}$ A main finding of this literature is that subjects on average over-consume relative to the unconditional optimum in the early periods of life. Consequently, they accumulate too little wealth and so they under-consume relative to the unconditional optimum in later periods of life. While many of these papers make use of more complicated lifecycle income processes than we consider in this paper, (e.g. stochastic income processes), none of these prior experimental studies aims to understand the effect of different social security replacement rates by consid-

\footnotetext{
${ }^{2}$ A similar argument has also been made in Kotlikoff et al. (1982), Feldstein (1985), and Akerlof (1991).

${ }^{3}$ For example, see Johnson et al. (2001); Fehr and Zych (1998, 2008); Ballinger et al. (2003); Carbone and Hey (2004); Carbone (2006); Brown et al. (2009); Ballinger et al. (2011); Feltovich and Ejebu (2014); Carbone and Duffy (2014); Meissner (2014); Meissner and Rostam-Afschar (2014); Koehler et al. (2015); Levy and Tasoff (2015b).
} 
ering a deterministic drop in endowments in later periods of lifetimes using the framework of induced utility. ${ }^{4}$ Further, most of previous studies employ stochastic income processes, and it is not clear whether subjects deviate from the optimal path because they misunderstand the probabilities of different income possibilities or they understand these probabilities but are unable to calculate the optimal solution. Thus, we contribute to this experimental literature by studying settings where there is: 1) a known, deterministic income process, sometimes involving a drop-off in income upon retirement and 2) there always exists an optimal consumption path which we can use as a reference point to evaluate subject behavior. Indeed, this optimal consumption path is kept constant across all of our treatments, enabling a clear analysis of the effect of different income profiles on subjects' consumption and saving plans.

The second strand of the literature uses survey or field experiment methods to evaluate the efficacy of various interventions designed to aid in retirement planning (Brown et al., 2013, 2016; Liebman et al., 2015). Our research complements these studies by focusing on lifecycle consumption and saving decisions. A third strand of the literature focuses on explaining the puzzle of why retirees do not dissave much in retirement (Kotlikoff et al., 1981; Hurd et al., 1989; De Nardi, 2004; De Nardi et al., 2010; Kopecky and Koreshkova, 2014; Ameriks et al., 2015). Our contribution is to propose an alternative explanation that the consumption decisions of some retirees are biased towards their low levels of non-capital income, and hence they dissave at a slower rate than the rational choice model predicts.

A final strand of the literature uses behavioral models to explain the puzzles of consumption and saving decisions in the data. For instance, Laibson (1997) and O'Donoghue and Rabin (1999) propose that individuals may have hyperbolic preferences, leading them to consume more today than is optimal given that no commitment device is available. Loewenstein and Prelec (1992) argue that the utility function involves a reference point such that the taste

\footnotetext{
${ }^{4}$ Koehler et al. (2015) is the only study that includes a retirement phase, but they do not design treatments with different replacement rates or induce subjects to hold a certain utility over differing consumption amounts.
} 
for gains and losses are asymmetric, and framing and prior expectations affect intertemporal choices. Shefrin and Thaler (1988) introduce mental accounting to the lifecycle problem and argue that individuals treat different components of wealth to be non-fungible. Levy and Tasoff (2015a) argues that individuals may under-predict the compound interest earned on investments, and hence save too little. Our analysis is in support of the theory developed by Campbell and Mankiw (1989) and Mankiw (2000): the economy may be composed of two types of individuals - one type solves the intertemporal choice problem conditional on their existing wealth and the other type simply consumes their endowment (income) in every period. Given these two types, in the aggregate, the average level of consumption will be greater than optimal in periods where the current endowment is greater than the optimal path (e.g. early working age periods) and less than optimal in periods (e.g., retirement) where the current endowment is smaller than the optimal path.

The remainder of the paper proceeds as follows. Section 2 describes the theoretical framework that motivates the design of our experiment; Section 3 explains the experimental environment and choice of model parameters; Section 4 reports our main experimental findings; Section 5 compares the fit of several alternative models to the data; Section 6 provides further discussion about the two type model; Finally, Section 7 provides a summary and suggestions for future research.

\section{Theoretical Framework}

Our theoretical framework is the standard, intertemporal model of lifecycle consumption and savings choices originating in the work of Modigliani and Brumberg (1954) and Friedman (1957). We adopt this framework as it remains the workhorse approach to the modeling of household consumption and savings behavior in the macroeconomic and finance literatures and we wish to present our results using a framework that is familiar to this audience, as we 
hope to move the discussion of lifecycle planning in a direction that takes greater account of departures from the rational choice framework. We further restrict attention to the case of complete markets and no uncertainty as we wish to make the environment as simple as possible for our human subjects. As noted in the introduction, the world is far more complex - income is uncertain and markets are incomplete - but we wish to start with the simplest possible framework; if subjects are not able to optimally save for retirement in this simple setting, then it is unlikely that they will do better in more complicated settings.

The theoretical framework can be described as follows. Each household $i$ makes consumption and savings decisions in each of periods $p=1,2, . . P$, where the final period, $P$, is perfectly known. Household $i$ 's endowment process over the lifecycle is also perfectly known, and denoted by $\left\{e_{i p}\right\}_{p=1}^{P}$. Household $i$ 's objective is to:

$$
\max _{\left\{c_{i p}, a_{i(p+1)}\right\}_{p=1}^{P}} \sum_{p=1}^{P} u\left(c_{i p}\right)
$$

subject to

$$
\begin{gathered}
c_{i p}+\frac{a_{i(p+1)}}{1+r}=e_{i p}+a_{i p}, \quad \forall p \\
a_{i(p+1)} \geq 0 \quad \forall p, \text { and } a_{i 1}=0 .
\end{gathered}
$$

Here, $c_{i p}$ denotes household $i$ 's period $p$ consumption, $a_{i(p+1)}$ denotes household $i$ 's initial assets for period $p+1$, and $r>0$ is an exogenous fixed and known rate of interest; again, with the aim of simplicity, we are thus considering a partial equilibrium environment. We also impose a no-borrowing constraint, which should not be binding given a positive $r$ and the specified utility function; again the rationale is simplicity, though we recognize that borrowing constraints can be empirically important in lifecycle consumption and savings 
decisions. ${ }^{5}$ Notice further that we are ignoring any time discounting (i.e., we are setting the discount factor, $\beta=1$ ) as our experiment will be conducted over several hours in a laboratory setting. The utility function $u(\cdot)$ is assumed to be increasing and concave, and represents the payoff function by which subject's period by period consumption choices earn them monetary payments. Compared with an alternative setting without induced utility, the introduction of $u(\cdot)$ yields a unique, optimal consumption path against which we can compare the behavior of our subjects. ${ }^{6}$ We adopt a concave utility function specification as this implies that intertemporal smoothing of consumption is desirable (as in the lifecycle theory).

Given the concavity of the utility function and given a lifetime endowment sequence, $\left\{e_{i p}\right\}_{p=1}^{P}$, it is straightforward to calculate, by working backwards, the solution to the maximization problem stated above, which we refer to as the unconditionally optimal path and denote by $\left\{c_{i p}^{* *}, a_{i(p+1)}^{* *}\right\}_{p=1}^{P}$. Recognizing that subjects may make decision errors over their lifetimes, we will also consider their behavior relative to the conditionally optimal consumption path, which we denote by $\left\{c_{i p}^{*}\right\}_{p=1}^{P}$. Formally, $c_{i p}^{*}$ involves re-optimization at each new period of the lifecycle, based on current asset holdings, and is the solution to:

$$
\max _{c_{i p}} \sum_{j=p}^{P} u\left(c_{i j}\right)
$$

\footnotetext{
${ }^{5}$ Allowing borrowing, we would have to specify borrowing constraints, which would further complicate the decision space of subjects. The optimal path for the model that we do implement does not require any borrowing.

${ }^{6}$ It would, of course, be interesting to study how individuals make consumption and savings decision over their lifetimes given their own, "homegrown" preferences, but it might be difficult to determine the nature of those preferences and thus the optimal consumption path, hence we decide to induce preferences.
} 
subject to

$$
\begin{array}{r}
c_{i j}+\frac{a_{i(j+1)}}{1+r}=e_{i j}+a_{i j}, \quad \forall j \geq p \\
a_{i(j+1)} \geq 0, \quad \forall j \geq p \text { and } a_{i p} \text { is given. }
\end{array}
$$

\section{Experimental Design}

In our experiment, we set $P=25$ and $u(c)=0.2 \ln (0.01 c+1)$. Assuming that each period in the model represents 2.3 years, setting $P=25$ periods corresponds to an economy where people enter at age 23 and exit at age 79. More precisely, the first 17 periods correspond to ages 23-60 and represent the period of the lifecycle in which people work and receive (after-tax) earnings; the last 8 periods correspond to ages 61-79 and represent the period when people are retired and receive benefit income or consume out of their accumulated asset positions. We induce a log utility function over consumption because the implied coefficient of relative risk aversion of 1 finds some support in the empirical literature (Chetty, 2006). The interest rate, $r$, was set at 10 percent per model period and remained constant across all of our treatments; this choice implies an average annual real return of 4.5 percent on long term investments (Munnell et al., 2013).

We consider four different lifecycle endowment profiles, which comprise our four main experimental treatments. All four endowment profiles have the same present value, that is, for any two treatments $i \neq j$, it was always the case that:

$$
\sum_{p=1}^{P} \frac{e_{i p}}{(1+r)^{p}}=\sum_{p=1}^{P} \frac{e_{j p}}{(1+r)^{p}}
$$

Our four treatments differ according to the distribution of endowments over the lifecycle, or, equivalently, the social security tax and benefit scheme. For instance, the endowment 
flow in treatment one (T1) is at a constant 500 "tokens" for the first 17 (work) periods, but in the last 8 (retirement) periods, the endowment amount drops to 200 tokens, which replaces 40 percent of the average endowment received during the working periods. We chose a 40 percent replacement rate because that is the replacement rate of social security benefits for a worker who earns the median U.S. income (Feldstein, 2005). Treatment two (T2) is designed to represent an economy without a social security system, in which subjects receive a higher endowment of 526 tokens during the first 17 working periods as compared with T1 as they pay no tax, but they now receive a zero endowment in each of the final 8 periods of retirement. Hence, subjects in T2 must more actively save during their working years in order to have any consumption in the retirement phase of their lives. Treatment three (T3) is an extreme case where subjects receive a single lump-sum endowment of 4,644 tokens in the very first period of their lives and 0 in each of the remaining 24 periods, while treatment four (T4) represents the opposite extreme case where subjects receive a constant endowment of 465 tokens in each of the 25 periods of their lifetimes, which is lower than the endowment received during the working periods of $\mathrm{T} 1$ and $\mathrm{T} 2$. Treatment $\mathrm{T} 4$ can be viewed as a social security system that uses a greater payroll tax to fund a more generous retirement plan, which replaces 100 percent of pre-retirement after-tax earnings. Figure A2 in Appendix B provides a visual illustration of these four different endowment processes, which were also shown and explained to subjects in our experiment.

The induced utility function serves as a mapping between subjects' consumption choice (the number of tokens they consume) and their period money earnings. In each period, subjects are asked to decide how many tokens they wish to convert into money using the conversion rate implied by the utility function. The remaining amount of tokens are automatically saved for the future and earn the fixed interest rate of $10 \%$ per period. Following the completion of the final, 25th period, any tokens that were not converted into money were lost (had zero redemption value) and this fact was made known to subjects in the written 
instructions. This payment structure implies that maximization of monetary payoff in the experiment is equivalent to maximization of lifetime utility in the theoretical model. A sample screenshot for the decision process as well as the instructions distributed to subjects at the beginning of the experiment are provided in Appendix A.

In each session, subjects were first assigned to one endowment treatment condition for two, 25-period "sequences" (lifetimes), and then they are assigned to a second endowment treatment for an additional two, 25-period sequences. We repeated each endowment condition twice to allow for some learning by subjects. In each experimental session, we implemented just one of four different treatment orders: T1-T2, T2-T1, T3-T4, or T4-T3. Thus subjects who participated for example in a session with treatment order T1-T2 played two, 25-period sequences under the endowment profile of treatment 1 and then played 2 additional 25-period sequences under the endowment profile of treatment 2. In all cases, subjects were instructed about the endowment profile of the first treatment, and following completion of the two lifecycle sequences under that endowment profile, they were instructed about the endowment profile of the second treatment. The change in endowment profile is the only change between treatments; all other factors, e.g. the utility function, the rate of interest on savings, and the number of periods of decision-making (25) were held constant.

Subjects' actual monetary payoff was the sum of their experimental lifetime utility from two, randomly selected sequences (lifetimes), one separately from each of the two treatments of a session, plus a show-up payment. Since subjects did not know which of the two sequences they played of each treatment would be randomly chosen for payment, they were incentivized to perform their best in each sequence. Subjects were paid in cash at the end of a session with the average payment being around $\$ 25$ per subject.

Given the model parameters, Figure 1 plots the optimal lifecycle consumption and asset profiles for each treatment. Notice that the no borrowing constraint is never binding if subjects behave rationally. As shown in Figure 1(a), the optimal consumption path is 


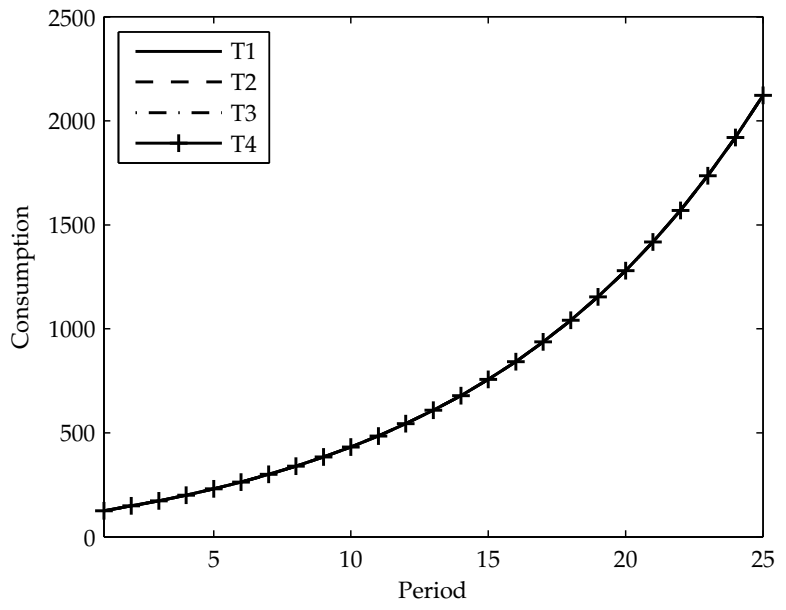

(a) Consumption

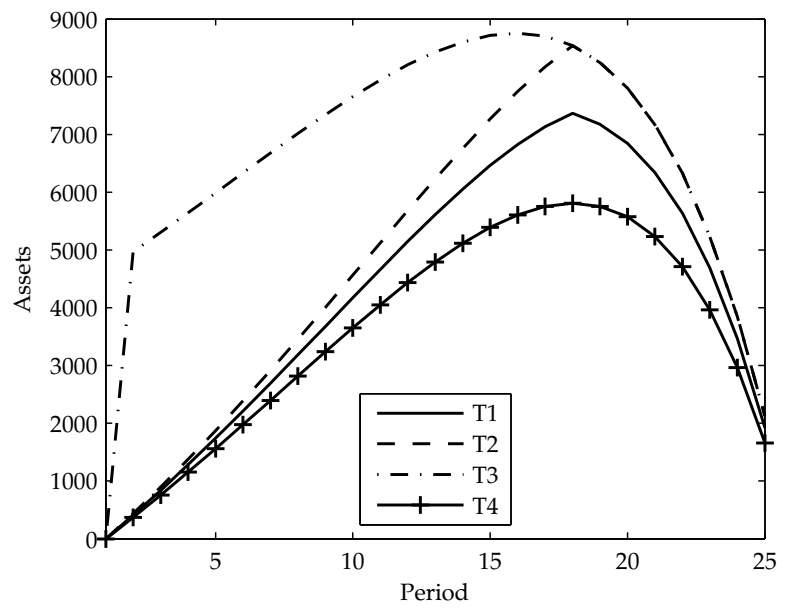

(b) Assets

Figure 1: Optimal decisions implied by rational choice theory

upward sloping and is the same across all four treatments. However, since the distribution of endowments differs by treatment, the optimal asset path varies across the four treatments. In particular, to offset for the sharp drop-off in endowments in later periods of life, subjects need to save more in treatments T2 and T3, as compared with treatments T1 and T4.

\section{Findings}

The experimental subjects were all undergraduates at the University of California, Irvine who had no prior experience participating in any of our experimental treatments. No subject was allowed to participate in more than one treatment order (experimental session). The raw data are composed of 28, 32, 30, and 29 subjects for each of the four treatment orders T1-T2, T2-T1, T3-T4, and T4-T3, respectively. As all of our treatments are individual-choice (there are no interactions between subjects), we treat each subject in a 25 period sequence as a single observation. Table 1 reports on some characteristics of our design.

We summarize our experimental results as a number of different findings. 
Table 1: Characteristics of experimental sessions

\begin{tabular}{llccc}
\hline \hline & Endowments & No. Obs. & Average earnings & \multicolumn{1}{c}{$\begin{array}{c}\text { Earnings } \\
\text { if converting endowments }\end{array}$} \\
\hline T1 & 500 for $p=1,2, \cdots, 17$, & 120 & $\$ 8.50$ & $\$ 7.85$ \\
& $\begin{array}{l}200 \text { for } p=18,19, \cdots, 25 \\
\text { T2 }\end{array} \quad \begin{array}{l}526 \text { for } p=1,2, \cdots, 1, \\
0 \text { for } p=18,19, \cdots, 25\end{array}$ & 120 & $\$ 8.56$ & $\$ 6.24$ \\
T3 & $\begin{array}{l}4,644 \text { for } p=1, \\
\quad 0 \text { for } p=2,3, \cdots, 25 .\end{array}$ & 118 & $\$ 8.31$ & $\$ 0.77$ \\
T4 $\quad 465$ for $p=1,2, \cdots, 25$. & 118 & $\$ 8.70$ & $\$ 8.66$ \\
\hline \hline
\end{tabular}

Note: The unit of observation is one-subject-one-25-period sequence. The earnings from adopting the unconditionally optimal consumption path in a sequence is $\$ 9.78$.

Finding 1 The quality of subjects' decisions improves with experience.

We use three measures to compare the quality of decisions. The first measure is subjects' final earnings, corresponding to the lifetime utility in the model. The second measure is the RootMean-Square-Deviation (RMSD) of consumption choices from the unconditionally optimal level, which reflects the deviation of the choice variables from the level that maximizes lifetime utility. The last measure is the RMSD of assets from the unconditionally optimal level, which reflects the deviation of the endogenous state variable, wealth, from the level that maximizes lifetime utility.

The RMSD of the outcome variable $z \in\{c, a\}$ for subject $i$ in sequence $s$ is defined as follows:

$$
R M S D_{i s}^{z}=\sqrt{\frac{1}{P} \sum_{p=1}^{P}\left(z_{i s t p}-z_{t p}^{* *}\right)^{2}} .
$$

where $z_{i s t p}$ is the value of $z$ for subject $i$ in sequence $s$ of treatment $t$ for period $p$. $z_{t p}^{* *}$ is the associated unconditionally optimal level of treatment $t$ for period $p$.

Table 2 reports on the average final earnings and the average RMSD for each sequence, 
S1-S4, and whether the difference between the paired observation of two sequences follows a symmetric distribution around zero using the Wilcoxon signed-rank test. In each panel, Line 1 compares sequence 1 with each of sequences 2,3 , and 4 ; line 2 compares sequence 2 with that of sequences 3 and 4 and line 3 compares sequence 3 with sequence 4 . It is clear that among all sequences, sequence 1 has the smallest final earnings (panel A), and the largest RMSD of consumption (panel B) or assets (panel C), indicating the quality of individual decisions improves with experience. As shown in lines 2-4 however, the difference in means among the other three sequences is quite small, suggesting that subjects do not learn a lot starting from the second sequence of the lifecycle. Furthermore, there is no evidence showing that decisions are converging to rational choice model predictions beyond the first repetition; even in the final sequence, subjects' decisions deviate substantially from the unconditionally optimal levels, resulting in an average 11.9 percent reduction in lifetime utility compared with the unconditionally optimal path.

Finding 2 The flow of endowments affects the quality of subjects' decisions, though such differences weaken with experience.

Table 3 reports on the average final earnings for each treatment in each sequence and whether the probability of an observation from treatment $i$ exceeding an observation from treatment $j \neq i$ equals the probability of an observation from treatment $j$ exceeding an observation from treatment $i$ using the Wilcoxon rank-sum test. ${ }^{7}$ We focus first on sequence 1 of each treatment. Panel A shows that in this first sequence (S1), subjects who are randomly assigned to $\mathrm{T} 1$ are significantly more likely to have earnings smaller than those who are randomly assigned to T2 (at the 10 percent level), or to T4 (at the 1 percent level). In addition, column 4 in the same Panel A indicates that subjects who are randomly assigned to T4 are significantly more likely to have earnings greater than those who are randomly assigned

\footnotetext{
${ }^{7}$ Pairwise treatment differences in the RMSDs of consumption from the unconditionally optimal path show a similar pattern, and are therefore relegated to Table A1 in Appendix B.
} 
Table 2: Comparison across sequences

\begin{tabular}{|c|c|c|c|c|}
\hline & $\begin{array}{l}\text { Mean } \\
(1)\end{array}$ & $\begin{array}{l}\mathrm{S} 2 \\
(2)\end{array}$ & $\begin{array}{l}\text { S3 } \\
(3)\end{array}$ & $\begin{array}{l}\text { S4 } \\
(4)\end{array}$ \\
\hline \multicolumn{5}{|c|}{ Panel A : Final earnings } \\
\hline S1 & 8.10 & $<* * *$ & $<* * *$ & $<* * *$ \\
\hline $\mathrm{S} 2$ & 8.65 & & $<$ & $<^{*}$ \\
\hline S3 & 8.61 & & & $<$ \\
\hline S4 & 8.71 & & & \\
\hline \multicolumn{5}{|c|}{ Panel B: RMSD of Consumption } \\
\hline S1 & 865.96 & $>* * *$ & $>^{* *}$ & $>* * *$ \\
\hline S2 & 704.48 & & $>$ & $>* *$ \\
\hline S3 & 730.69 & & & $>$ \\
\hline S4 & 662.82 & & & \\
\hline \multicolumn{5}{|c|}{ Panel C: RMSD of Assets } \\
\hline S1 & 3787.49 & $>* * *$ & $>* * *$ & $>* * *$ \\
\hline $\mathrm{S} 2$ & 3156.15 & & $>$ & $>$ \\
\hline S3 & 3134.48 & & & $>$ \\
\hline S4 & 3070.37 & & & \\
\hline
\end{tabular}

Note: Column (1) reports the average value for each sequence. Columns (2)-(4) reports the sign of the sum of the signed rank and its significance $\left({ }^{* *}>0.01,{ }^{* *}>0.05,{ }^{*}>0.1\right)$ using the Wilcoxon signed-rank test. $<$ indicates by comparing the row sequence to the column sequence that the sum of the signed rank is negative, while $>$ indicates the opposite. 
to any of the other three treatments in S1. Hence, given that subjects' decisions deviate from theoretical predictions, making the endowment flow perfectly constant over time, as in $\mathrm{T} 4$, induces subjects to make better intertemporal allocation decisions and to earn a higher lifetime utility. The lifetime utility in S1, however, is not a monotonic function of the number of tokens received in the last 8 periods (or the ratio of tokens received in the last 8 periods to that of the initial 17 periods), since average earnings in T1 are smaller than those in T2.

With experience, this treatment effect dissipates and becomes statistically insignificant in any pairwise comparisons of treatments for the final fourth sequence, S4 (Panel D).

Table 3: Final earnings by treatment in each sequence

\begin{tabular}{|c|c|c|c|c|}
\hline & $\begin{array}{l}\text { Mean } \\
(1)\end{array}$ & $\begin{array}{l}\mathrm{T} 2 \\
(2) \\
\end{array}$ & $\begin{array}{l}\text { T3 } \\
\text { (3) } \\
\end{array}$ & $\begin{array}{l}\mathrm{T} 4 \\
(4) \\
\end{array}$ \\
\hline \multicolumn{5}{|c|}{ Panel A: S1 } \\
\hline T1 & 7.79 & $<^{*}$ & $<$ & $<* * *$ \\
\hline $\mathrm{T} 2$ & 8.27 & & $>$ & $<^{*}$ \\
\hline T3 & 7.86 & & & $<^{* *}$ \\
\hline $\mathrm{T} 4$ & 8.47 & & & \\
\hline \multicolumn{5}{|c|}{ Panel B: S2 } \\
\hline T1 & 8.45 & $<$ & $<^{* *}$ & $<* * *$ \\
\hline $\mathrm{T} 2$ & 8.59 & & $<$ & $<^{*}$ \\
\hline T3 & 8.70 & & & $>$ \\
\hline $\mathrm{T} 4$ & 8.84 & & & \\
\hline \multicolumn{5}{|c|}{ Panel C: S3 } \\
\hline T1 & 8.83 & $<$ & $>* * *$ & $<$ \\
\hline $\mathrm{T} 2$ & 8.78 & & $>^{* *}$ & $<$ \\
\hline T3 & 8.09 & & & $<* * *$ \\
\hline $\mathrm{T} 4$ & 8.73 & & & \\
\hline \multicolumn{5}{|c|}{ Panel D: S4 } \\
\hline T1 & 8.83 & $>$ & $>$ & $<$ \\
\hline $\mathrm{T} 2$ & 8.66 & & $>$ & $<$ \\
\hline T3 & 8.59 & & & $<$ \\
\hline $\mathrm{T} 4$ & 8.76 & & & \\
\hline
\end{tabular}

Note: Column (1) reports the average value for each treatment. Columns (2)-(4) reports the sign of the difference between treatments and its significance $\left({ }^{* * *}>0.01,{ }^{* *}>0.05,{ }^{*}>0.1\right)$ using the Wilcoxon rank-sum test. < indicates the sum of ranks (beginning at 1 for the smallest value) of the row treatment is smaller than that of the column treatment, and $>$ indicates the opposite. 
Finding 3 Subjects depart from both the unconditionally and the conditionally optimal paths for consumption. In particular, they over-consume in the early periods and under-consume in later periods of a lifecycle.

Figure 2 presents the average period-by-period deviation from the unconditionally optimal path and the associated $95 \%$ confidence interval. ${ }^{8}$ This figure clearly indicates that decisions observed in the experiment depart from the unconditionally optimal decisions implied by rational choice theory. Subjects consume more than the optimal level in early periods, and hence, relative to that optimal level, subjects accumulate fewer assets and can afford less consumption in the later periods of their lives.

To further illustrate the magnitude of deviations from the unconditionally optimal path, Figure 3 plots the average percentage deviation of consumption and assets relative to the unconditionally optimal path. As shown in Figure 3(a), in the first three periods, consumption in our experiment is around 100 percent greater than that predicted by the rational choice model. Over time, the percentage deviation becomes smaller and negative, and reaches its lowest level at around period 18 (the retirement period). As shown in Figure 3(b), observed assets are more than 40 percent lower than that predicted by the rational choice model from periods 7 through 22. The asset deviation becomes smaller toward the final periods, and the asset level is close to the unconditionally optimal level by the end of each 25-period sequence. Despite the significant difference in the average RMSD across treatments, we cannot identify any significant difference across treatments using a period-by-period comparison. As shown in Figure A3 in Appendix B, there is a very tiny difference in average consumption across treatments for each individual period in each sequence.

One concern with studying deviations from the unconditionally optimal path is that errors made in one period not only affect that period's deviation but also have a permanent effect on

\footnotetext{
${ }^{8}$ To account for possible serial correlation of decision errors over time within subjects, standard errors are clustered at the subject level.
} 


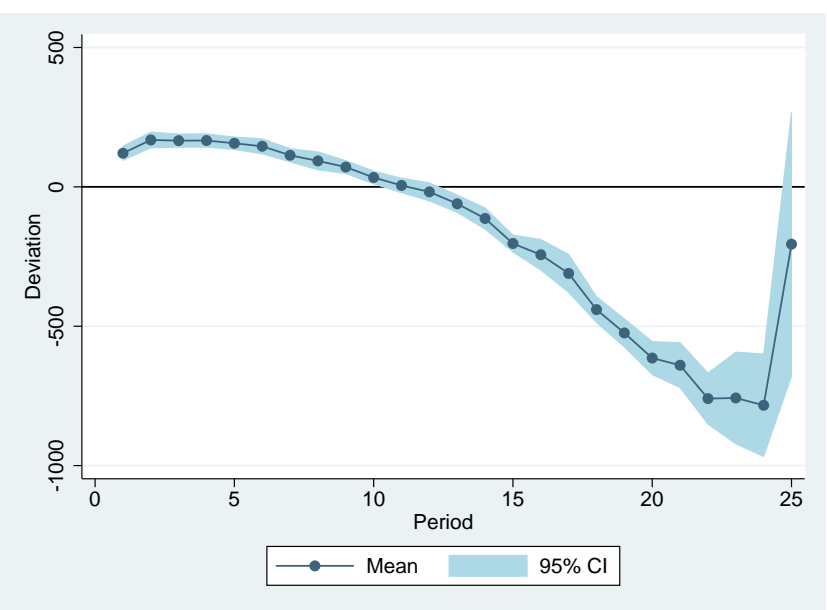

(a) Consumption

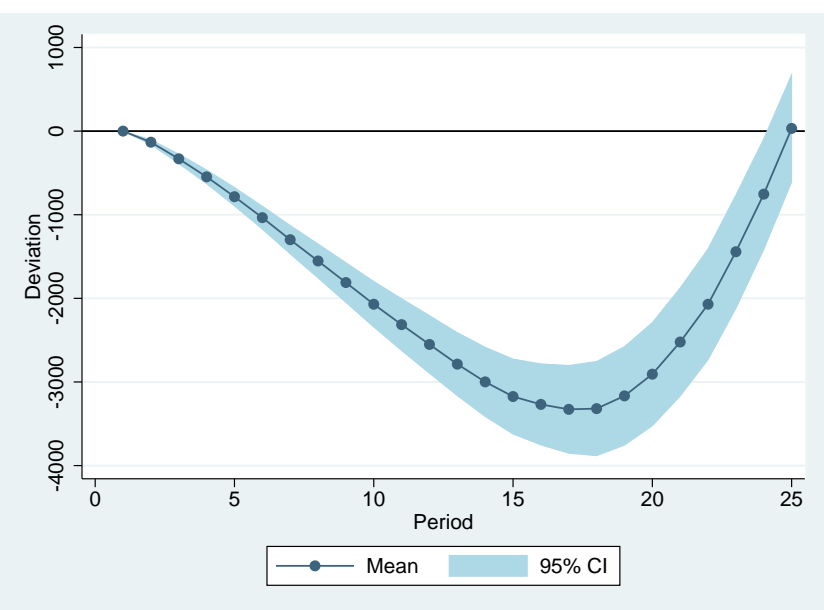

(b) Assets

Figure 2: Average deviation from the unconditionally optimal path

Note: The sample includes observations from all treatments and all sequences. Robust standard errors are clustered at the subject level.

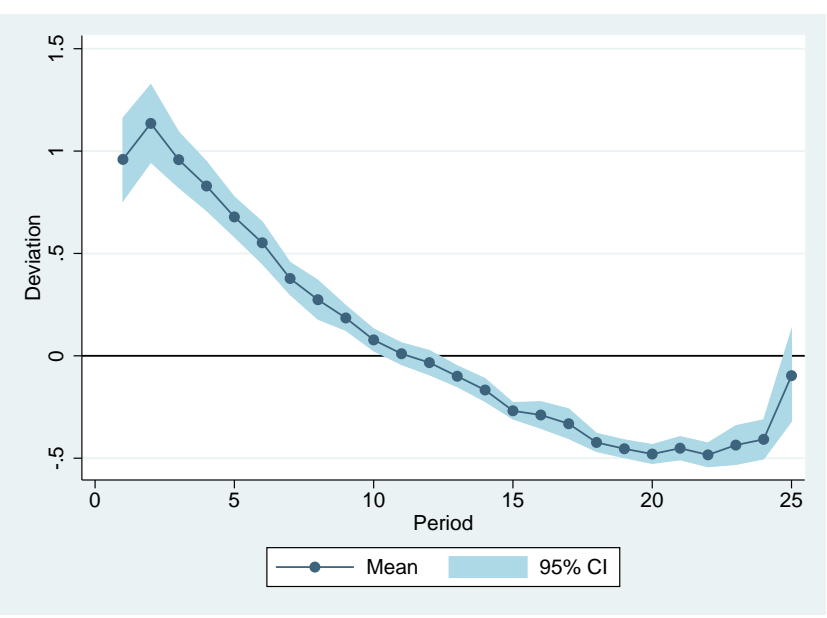

(a) Consumption

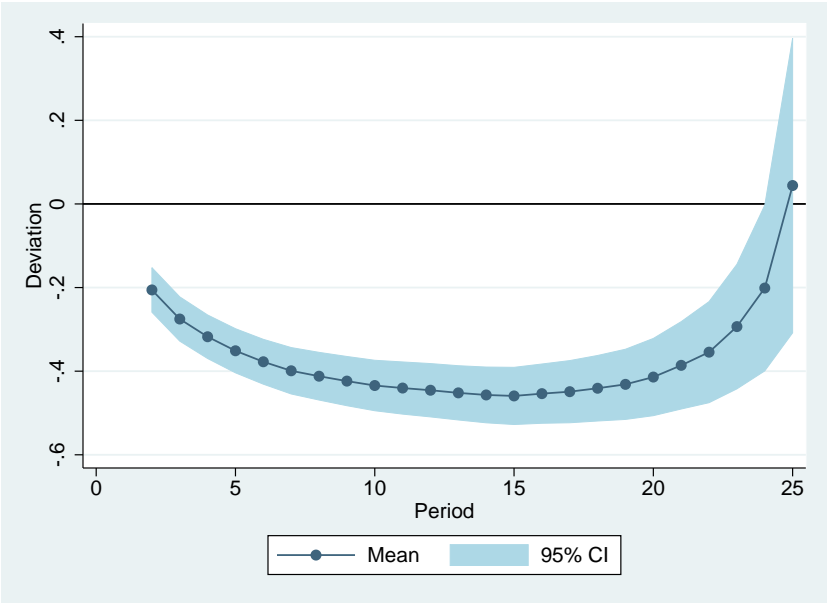

(b) Assets

Figure 3: Average percentage deviation from the unconditionally optimal path

Note: The sample includes observations from all treatments and all sequences. Robust standard errors are clustered at the subject level. Figure 3(b) omits the first periods value, since the initial asset is 0 .

all future deviations, even if subjects behave optimally from that period onwards. To address this concern, Figure 4 plots the average consumption deviation from the conditionally optimal path, which eliminates the effect of past decision errors on current deviations, along with the 
associated 95 percent confidence interval. Notice that since the deviation in consumption exactly mirrors the deviation in assets when evaluated relative to the conditionally optimal level, there is no need to present a separate figure for the asset profile. It transpires that the pattern for consumption deviations found in Figure 2(a) is preserved in Figure 4: relative to the conditionally optimal path, subjects continue to over-consume in early periods and under-consume in later periods. The only difference is that compared with Figure 2(a), in Figure 4, the deviation from the optimal path remains positive for an even longer period of time, and only around period 18 do subjects begin to consume less than the conditionally optimal level.

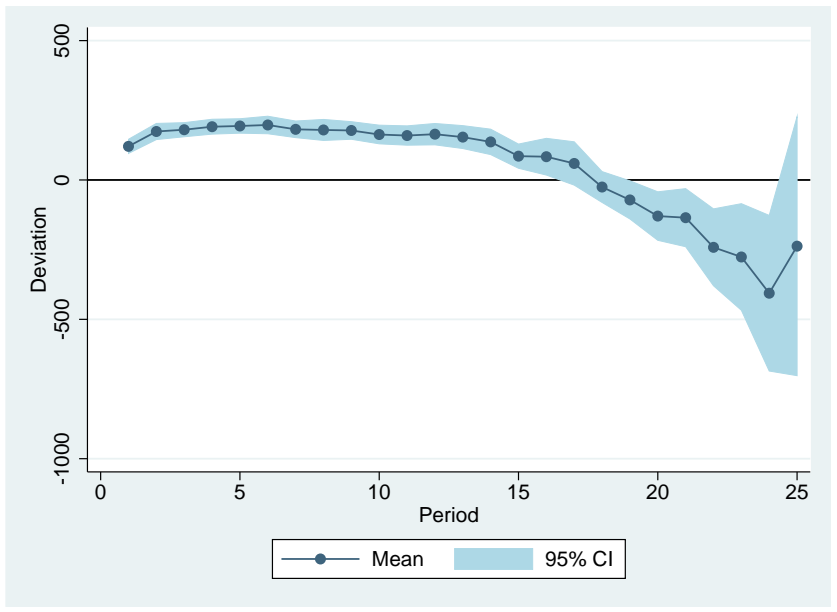

Figure 4: Average consumption deviation from the conditionally optimal path

Note: The sample includes observations from all treatments and all sequences. Robust standard errors are clustered at the subject level.

To understand whether the drop in this deviation over the life cycle is driven by treatments $\mathrm{T} 1$ and $\mathrm{T} 2$, which are the only two treatments with a reduction in endowments starting in period 18, Figure 5 plots the deviation of consumption from the conditionally optimal level for each of the four treatments individually. We find that for all four treatments, including treatments T3 and T4 that have no change in endowments at period 18, there is a similar reduction in the deviation of consumption from the conditionally optimal path beginning 


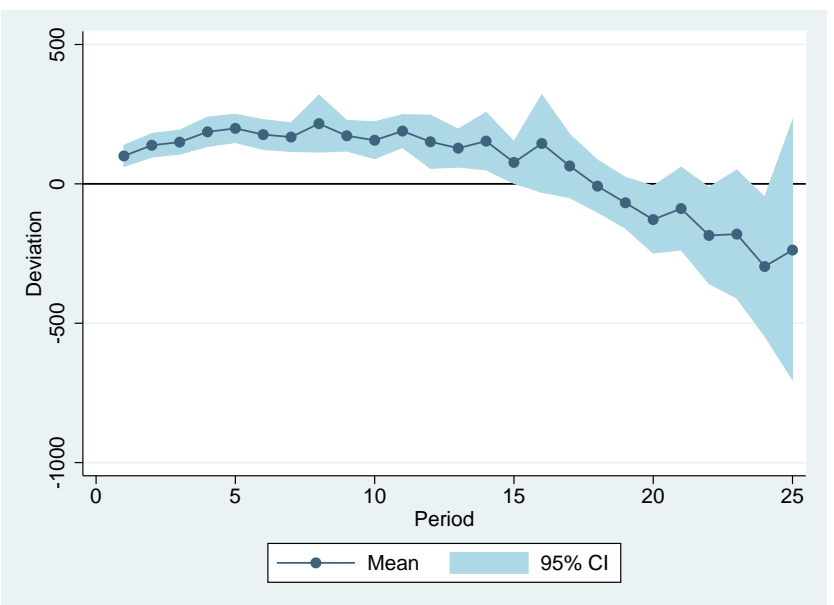

(a) $\mathrm{T} 1$

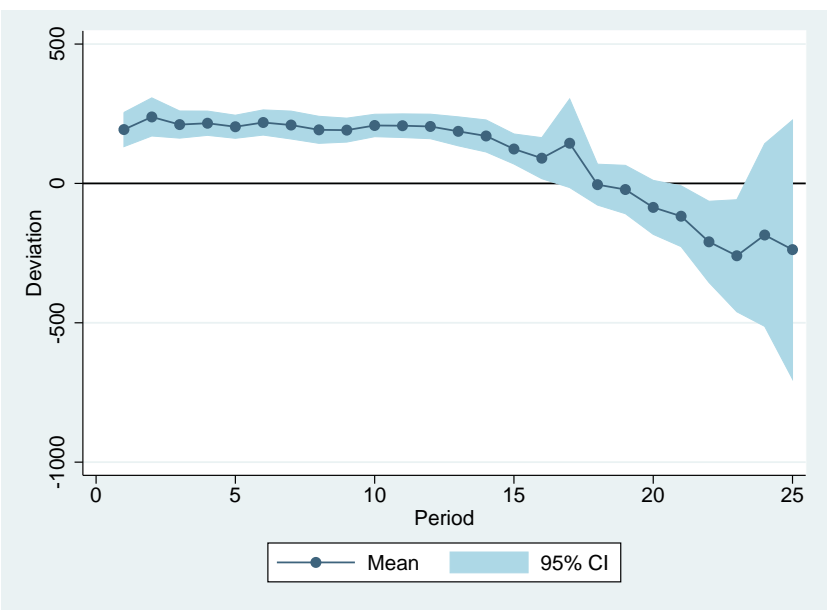

(c) T3

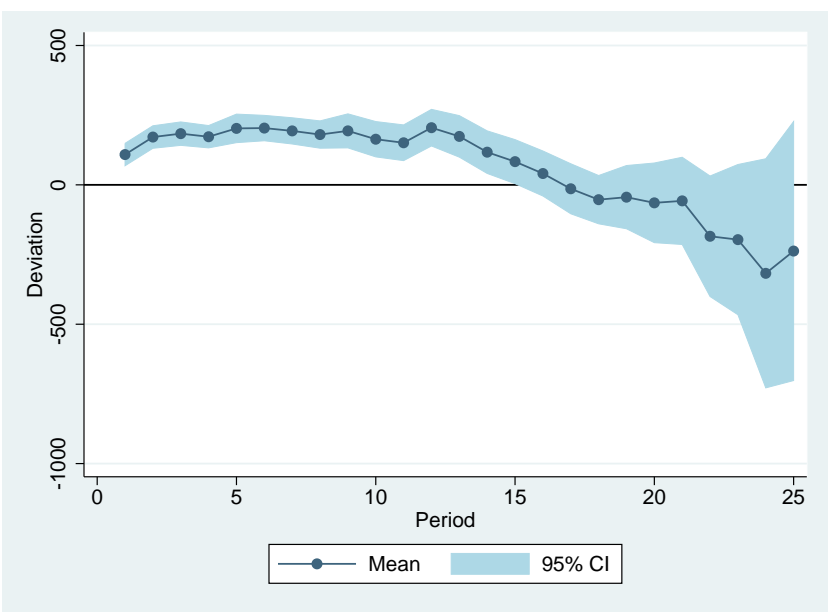

(b) $\mathrm{T} 2$

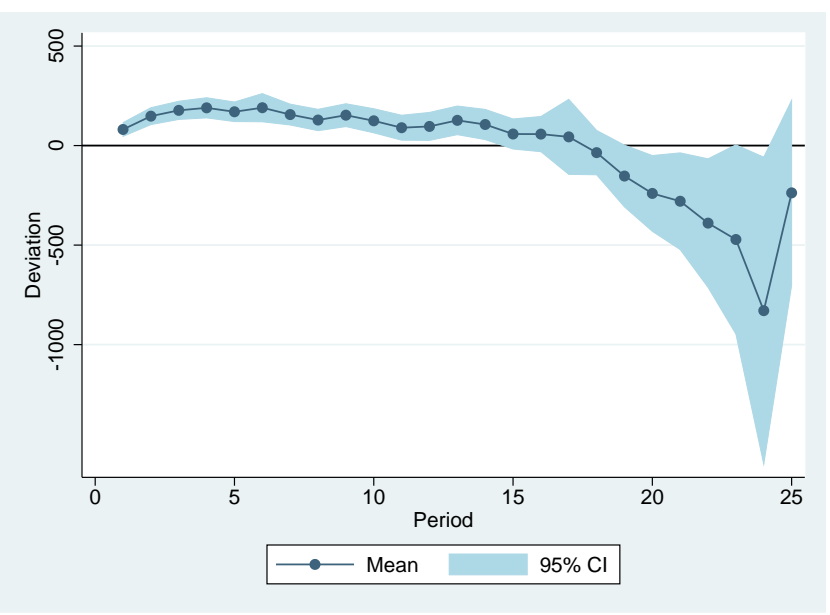

(d) $\mathrm{T} 4$

Figure 5: Average consumption deviation from the conditionally optimal path by treatment

Note: For each figure, the sample includes observations from all sequences. Robust standard errors are clustered at the subject level.

around period 5, indicating that the increasing gap between the conditionally optimal level and the endowment level is the likely cause of this reduction.

Finally, to understand whether the pattern of over-and-under consumption dissipates with experience, Figure 6 shows the consumption deviation from the conditionally optimal level for each sequence. As demonstrated by this figure, the over-and-under consumption pattern is quite persistent over time. 


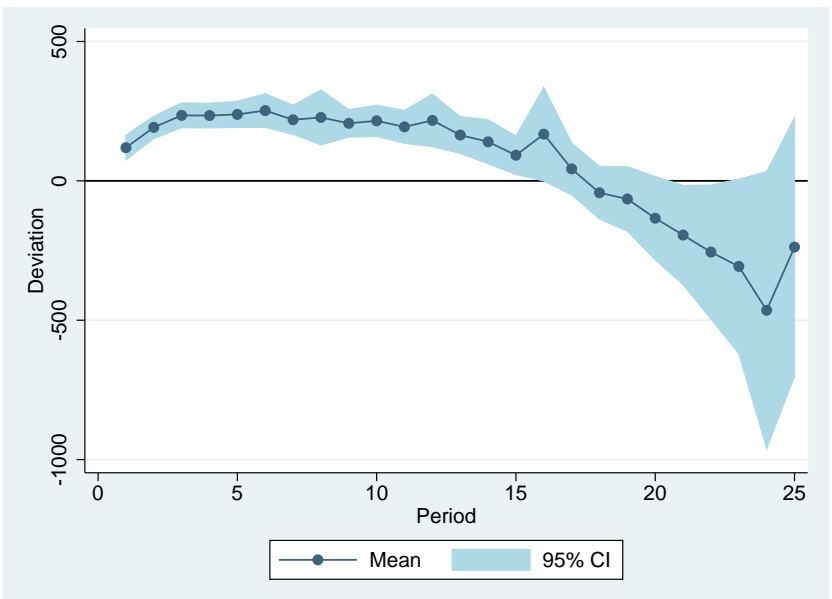

(a) S1

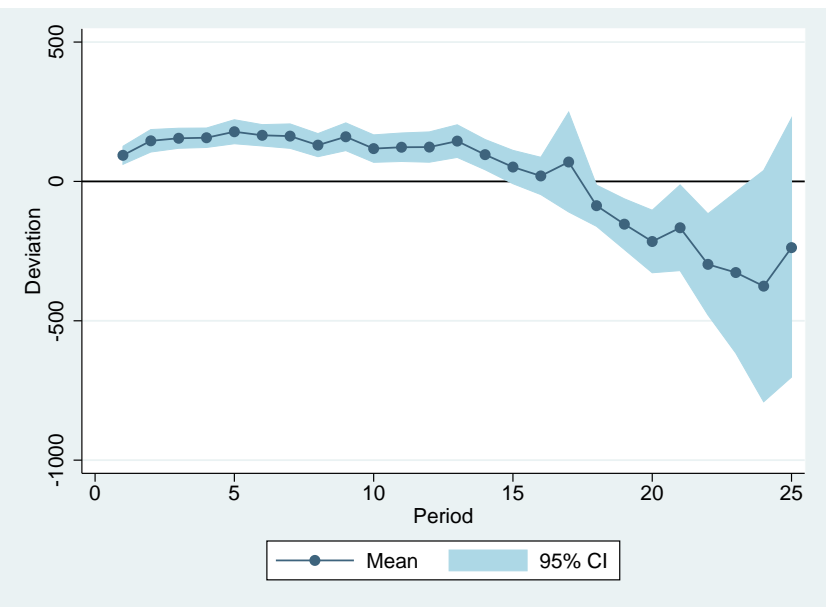

(c) S3

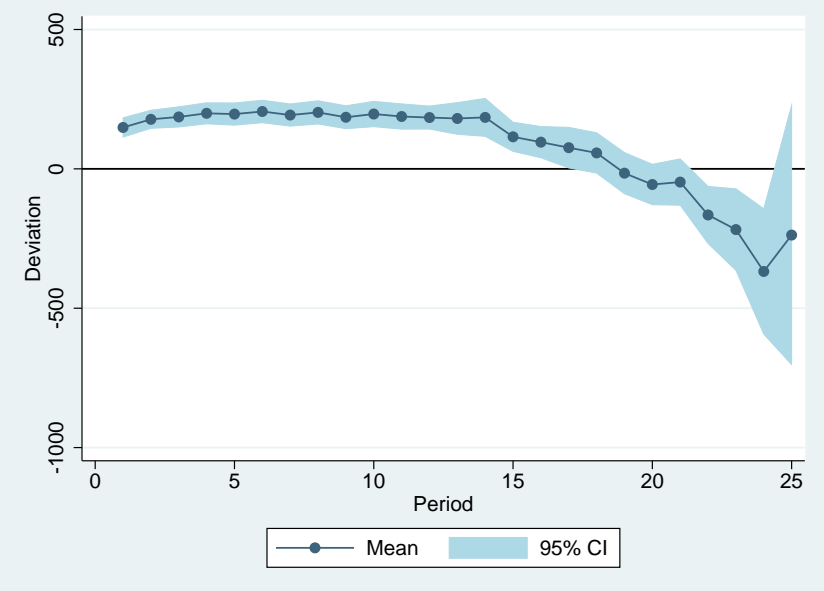

(b) S2

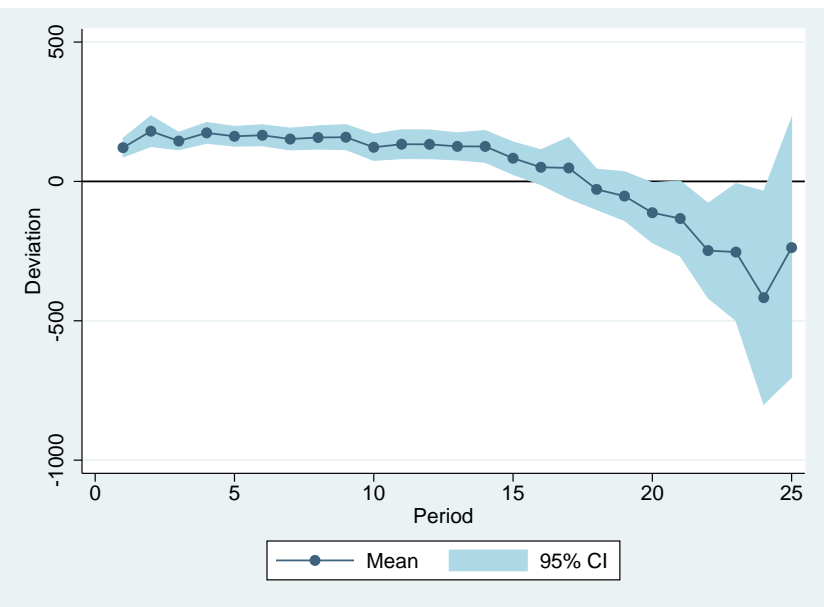

(d) $\mathrm{S} 4$

Figure 6: Average consumption deviation from the conditionally optimal path by sequence

Note: For each figure, the sample includes observations from all treatments. Robust standard errors are clustered at the subject level.

In sum, we identify a robust decision pattern that subjects, on average, over-consume in early periods and under-consume in later periods of the lifecycle relative to the conditionally optimal path. 


\section{Behavioral Models}

Motivated by the large deviation of consumption-saving decisions from the rational choice model prediction, in this section, we seek to understand which type of behavioral model could best fit our data and explain the over-and-under consumption lifecycle pattern. Specifically, we consider four classes of models as described below. Since in the last period, most subjects consume the conditionally optimal level, namely their accumulated assets and any endowment, as suggested in the experimental instructions, the analysis of this section and the next Section 6.2, will be based on observations for the first 24 periods of a sequence only.

The first class of model assumes that all individuals make decisions using the rational choice model - consuming the unconditionally optimal level ("Unc-optimal", number 1) or the conditionally optimal level ("C-optimal", number 2$).^{9}$

The second class of model assumes that all individuals make decisions using some heuristic rule of thumb, and we consider five different rules: hand to mouth, i.e., consuming 100 percent of endowment income, $e$, in every period (number 3); consuming a fraction $0<\zeta_{1}^{e}<1$ of endowment income, $e$, in every period (number 4) ; consuming a fraction $\zeta_{1}^{a}$ of assets, $a$, in every period (number 5); consuming a fraction $\zeta_{1}^{y}$ of new income $y=e+\frac{r a}{1+r}$, the sum of endowments and interest income in every period (number 6); and finally, consuming a fraction $\zeta_{1}^{x}$ of "cash-on-hand" $x=e+a$, the sum of endowments and assets, in every period (number 7). We treat these four different components of wealth-endowment, assets, new income, and cash-on-hand-as being non-fungible in the spirit of the mental accounting approach proposed by Shefrin and Thaler (1988). ${ }^{10}$

\footnotetext{
${ }^{9}$ The number in parentheses is the model number.

${ }^{10}$ We have also considered a more complicated rule of thumb wherein individuals consume out of three mental accounts: current endowment, current assets, and the present value of future endowment. We find that the two type model with hand to mouth consumers better fits the data than a (one-type, two-type or mixed-type) model with three mental accounts. We do not report on these alternative models in the paper, but we are happy to provide the results upon request.
} 
Table 4: Parameter estimates for one-type rule of thumb models

\begin{tabular}{ccccc}
\hline \hline Model number & $(4)$ & $(5)$ & $(6)$ & $(7)$ \\
\hline & $\zeta_{1}^{e}$ & $\zeta_{1}^{a}$ & $\zeta_{1}^{y}$ & $\zeta_{1}^{x}$ \\
& $0.47^{* * *}$ & $0.12^{* * *}$ & $0.58^{* * *}$ & $0.11^{* * *}$ \\
& $(0.03)$ & $(0.01)$ & $(0.03)$ & $(0.01)$ \\
\hline \hline
\end{tabular}

Note: The table presents estimates of $\zeta_{1}^{z}$ from equation (1) for models (4)-(7). The sample excludes observations from the final, 25th period. The number of observations is 11424 . Robust standard errors are clustered at the subject level. ${ }^{* * *}>0.01,{ }^{* *}>0.05,{ }^{*}>0.1$.

The parameters of interest, $\zeta_{1}^{z}, z \in\{e, a, y, x\}$ are estimated using the following equation:

$$
c_{i s t p}=\zeta_{1}^{z} z_{i s t p}+\varepsilon_{i s t p}
$$

where $c_{i s t p}$ is the consumption for subject $i$ in sequence $s$ of treatment $t$ for period $p, z_{i s t p}$ denotes the mental account variable, and $\varepsilon_{i s t p}$ is a random disturbance term that is clustered at the subject level. The estimates for $\zeta_{1}^{z} \mathrm{~s}$ are reported in Table 4.

The third class of model is a two-type model that is based on the dual process theory of psychology. According to the dual process theory, human decisions are affected by two different systems: system 1 is fast, instinctive and emotional, while system 2 is slower, more deliberative, and more logical (see, e.g. Kahneman (2011)). In the context of lifecycle consumption and savings decisions, we view the instinctive, system 1 choice as using a rule of thumb to decide on the consumption amount, while the more deliberative, system 2 choice is to consume the conditionally optimal consumption amount. For the system 1 choice, we consider the same five different rules of thumb in the same order as described before, which gives models (8)-(12). We note that these two systems have counterparts in the historical macroeconomic consumption literature: on the one hand, Keynes (1936) proposed that consumption was a function of current income, and for those with zero assets, current income equals their endowment. On the other hand, the permanent income approach of Friedman (1957) posits that consumption is a more deliberate, forward-looking function 
of permanent lifecycle income (wealth).

Within these five alternatives, the two type model where the system 1 choice (of type 1 agents) is to consume all endowment income and the system 2 choice (of type 2 agents) is to consume the conditionally optimal amount is a variant of the two-type model proposed in Campbell and Mankiw (1989) and Mankiw (2000). The difference is that we suppose that type 2 agents may make calculation errors and so they consume on average the conditionally optimal level instead of unconditionally optimal level.

Our two-type model is characterized by two sets of parameters: a vector that indicates the type for each subject in each sequence, and a parameter $\zeta_{2}^{z}$ that denotes the propensity to consume out of a particular mental account, $z \in\{e, a, y, x\}$, for those classified as type 1 agents. We estimate these parameters in four steps:

1. We estimate the following equation using the entire data sample:

$$
c_{i s t p}=\zeta_{2}^{z} z_{i s t p}+\xi_{i s t p}
$$

where $\xi_{i s t p}$ are random disturbances.

2. We calculate the RMSD of consumption from predicted consumption: $E_{p}\left(c_{i s t p}\right)=$ $\zeta_{2}^{z} z_{i s t p}$ for type 1 agents and $E_{p}\left(c_{i s t p}\right)=c_{i s t p}^{*}$ for type 2 agents, where $E_{p}(\cdot)$ is a conditional expectation function based on the information set at the beginning of period $p$.

3. If the RMSD using the type 1 prediction is smaller than that using the type 2 prediction, subject $i$ in sequence $s$ is classified as being type 1; otherwise, subject $i$ in sequence $s$ is classified as being type 2 .

4. We estimate Equation (2) using the sub-sample that is classified as being type 1 and we repeat steps 2 and 3 until the type vector stops changing. Note that for the two 
Table 5: Parameter estimates for two-type models

\begin{tabular}{lccccc}
\hline \hline Model number & $(8)$ & $(9)$ & $(10)$ & $(11)$ & $(12)$ \\
\hline & & $\zeta_{1}^{e}$ & $\zeta_{1}^{a}$ & $\zeta_{1}^{y}$ & $\zeta_{1}^{x}$ \\
& & $0.92^{* * *}$ & $0.05^{* * *}$ & $0.60^{* * *}$ & $0.05^{* * *}$ \\
Share of type 1 & 0.36 & $(0.05)$ & $(0.02)$ & $(0.08)$ & $(0.01)$ \\
\hline \hline
\end{tabular}

Note: The table presents estimates of $\zeta_{2}^{z}$ from equation (2) for models (9)-(12), and the share of subjects classified as type 1 for models (8)-(12). The sample excludes observations from the final, 25th period. The number of observations is 11,424 multiplied by the share of type 1. Robust standard errors are clustered at the subject level. ${ }^{* * *}>0.01,{ }^{* *}>0.05,{ }^{*}>0.1$.

type model with type 1 being hand to mouth consumers, we only implement steps 2 and 3 .

Table 5 reports the parameter estimates for the two type models. We see that the estimated propensity to consume out of endowment income (model 9) is very close to 1 , suggesting this particular model should be similar to the two-type model where type 1 agents are hand to mouth consumers.

The fourth and final class of model is a mixed-type model assuming that individuals' decisions are simultaneously affected by both system 1 and system 2 reasoning, reflecting the possibility that individuals may have two reference points so that their actual consumption is a weighted average of a rule of thumb (type 1) and the conditionally optimal level (type 2). For the system 1 part of the mixed-type model, we consider the same five different rules of thumb in the same order as described before, and produce models (13)-(17).

In general, this last class of models is characterized by two parameters: a weighting function $\gamma_{m}^{z}$ attached to the C-optimal choice, and a propensity to consume $\zeta_{m}^{z}$ out of a mental account $z \in\{e, a, y, x\}$, which are jointly estimated using the following equation:

$$
c_{i s t p}=\gamma_{m}^{z} c_{i s t p}^{*}+\left(1-\gamma_{m}^{z}\right) \zeta_{m}^{z} z_{i s t p}+\epsilon_{i s t p}
$$

where $\epsilon_{i s t p}$ are random errors. Model (13), the mixed-type model with hand to mouth 
Table 6: Parameter estimates for the mixed-type models

\begin{tabular}{cccccc}
\hline \hline Model number & $(13)$ & $(14)$ & $(15)$ & $(16)$ & $(17)$ \\
\hline & $\gamma_{m}$ & $\gamma_{m}^{e}$ & $\gamma_{m}^{a}$ & $\gamma_{m}^{y}$ & $\gamma_{m}^{x}$ \\
& $0.58^{* * *}$ & $0.53^{* * *}$ & $0.37^{* * *}$ & $0.42^{* * *}$ & $0.33^{* *}$ \\
& $(0.10)$ & $(0.11)$ & $(0.14)$ & $(0.12)$ & $(0.14)$ \\
& & $\left(1-\gamma_{m}^{e}\right) \zeta_{m}^{e}$ & $\left(1-\gamma_{m}^{a}\right) \zeta_{m}^{a}$ & $\left(1-\gamma_{m}^{y}\right) \zeta_{m}^{y}$ & $\left(1-\gamma_{m}^{x}\right) \zeta_{m}^{x}$ \\
& & $0.27^{* * *}$ & $0.05^{* * *}$ & $0.29^{* * *}$ & $0.06^{* * *}$ \\
& $(0.03)$ & $(0.01)$ & $(0.04)$ & $(0.01)$ \\
\hline \hline
\end{tabular}

Note: The table presents the estimates of $\gamma_{m}$ from equation (4) for model (13), and of $\gamma_{m}^{z}$ and $\left(1-\gamma_{m}^{z}\right) \zeta_{m}^{z}$ from equation (3) for models (14)-(17). The sample excludes observations from the final, 25th period. The number of observations is 11,424 . Robust standard errors are clustered at the subject level. ${ }^{* * *}>0.01$, ${ }^{* *}>0.05,{ }^{*}>0.1$.

consumers assumes that the marginal propensity to consume out of endowments is 1. For this model, we only need to estimate the weight attached to the C-optimal choice $\left(\gamma_{m}\right)$ from the following equation:

$$
c_{i s t p}=\gamma_{m} c_{i s t p}^{*}+\left(1-\gamma_{m}\right) e_{i s t p}+\epsilon_{i s t p}
$$

The estimated parameters are reported in Table 6.

Thus in total, we consider 17 different behavioral models: two rational choice models, five one-type rule of thumb models, five two-type models, and five mixed-type models. We calculate the RMSD of actual consumption decisions from the predictions of each of these 17 models, and report the results in Table 7 . We find that the two-type model with type 1 being hand to mouth consumers is the model that best fits the data. Using the Wilcoxon signed rank test, we reject the null hypothesis that the difference between the paired RMSD of this model (number 8) and other models follows a symmetric distribution around zero at the 1 percent significance level as Table 7 makes clear. Specifically, the average RMSD of this two-type model is 44.5 percent smaller than that of the Unc-optimum model (number 1), 25.3 percent smaller than that of the C-optimal model (number 2), 32.8 percent smaller than that of the best fit one-type rule of thumb model (number 7), and 24.5 percent smaller 
than that of the best fitting mixed-type model (number 13), although the difference in means is small within the class of two-type models.

One possible concern with the good match to the data of the two-type model with hand to mouth consumers is that it might be driven by observations in certain sequences and treatments. As a robustness check, we re-did the RMSD analysis using various subsamples of our data set, specifically, observations only from the first sequence, only from the last sequence, and only from the two treatments where there was a drop in endowment income in period 18 (T1 and T2). In addition, to separate the situation of voluntarily consuming endowments from the situation of being forced to consume endowments due to a no-borrowing constraint, we further restricted the sample to subjects who consumed less than their current available cash on hand, $x=e+a$, in every period (of the first 24 periods) of one sequence. For these alternative subsamples, we still find that the two-type model with hand to mouth consumers provides a best fit to our experimental data with the single exception that, in the sub-sample involving data on treatments T1 and T2 only, the two-type model with type 1 consuming a fraction of new income slightly outperforms the two-type model with hand to mouth consumers (see Tables A2-A5 in Appendix B).

To better illustrate the merit of the two-type model with hand to mouth consumers, Figure 7 plots the lifecycle consumption profile observed in the data and the profile predicted by four selected models: the C-optimal model (number 2), the best fit one-type rule of thumb model (number 7), the two-type model with hand to mouth consumers (number 8), and the best fitting mixed-type model (number 13). As shown in the figure, the two-type model closely matches the average amount of consumption over the life cycle in $\mathrm{T} 1$ and $\mathrm{T} 4$, while predictions of alternative models are further away from the experimental data. The two-type model does not provide a good match to the consumption decisions in the early periods of T2 and T3, but the two-type model still fits the data better than alternative models, and is the only model that can match consumption decisions in later periods for these two treatments. 


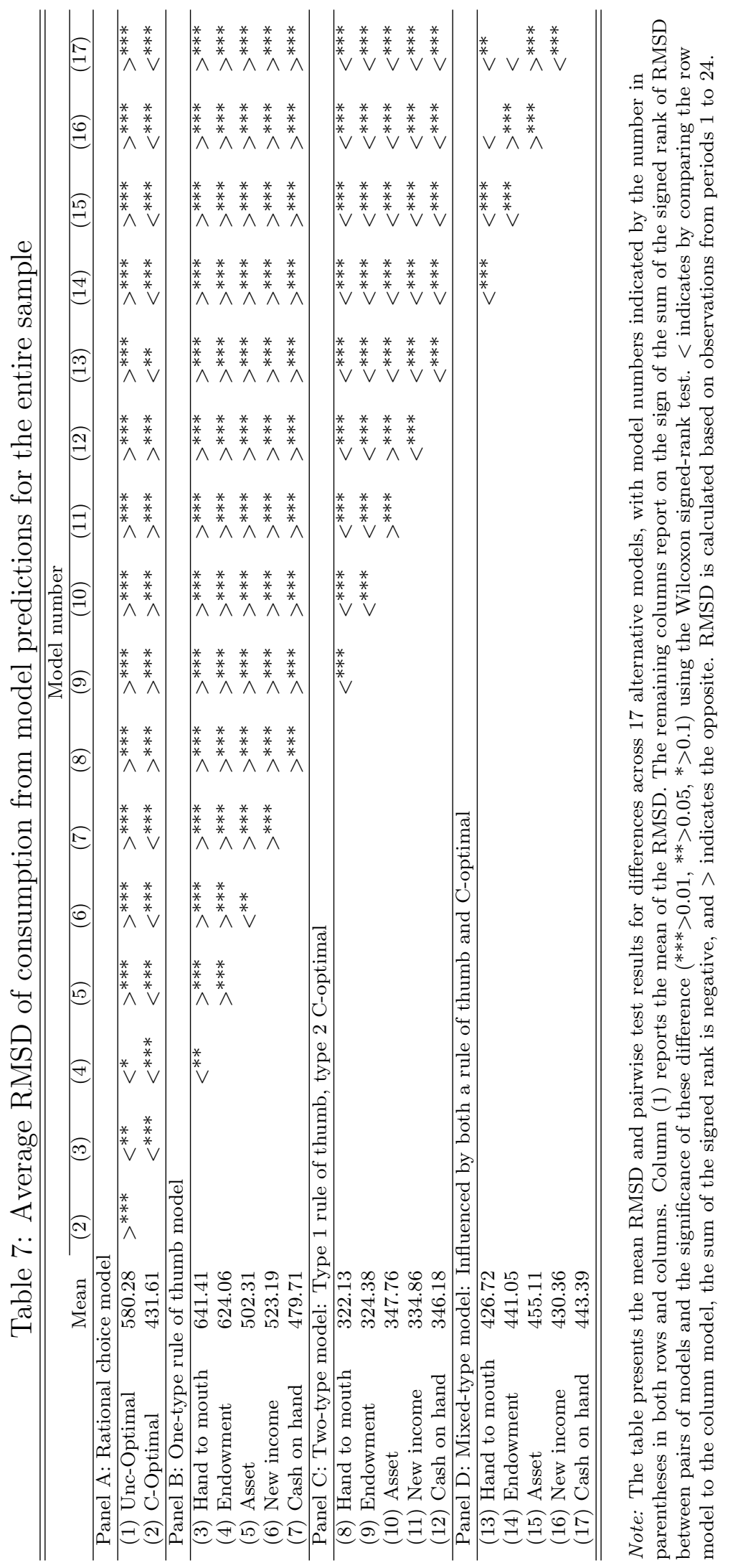




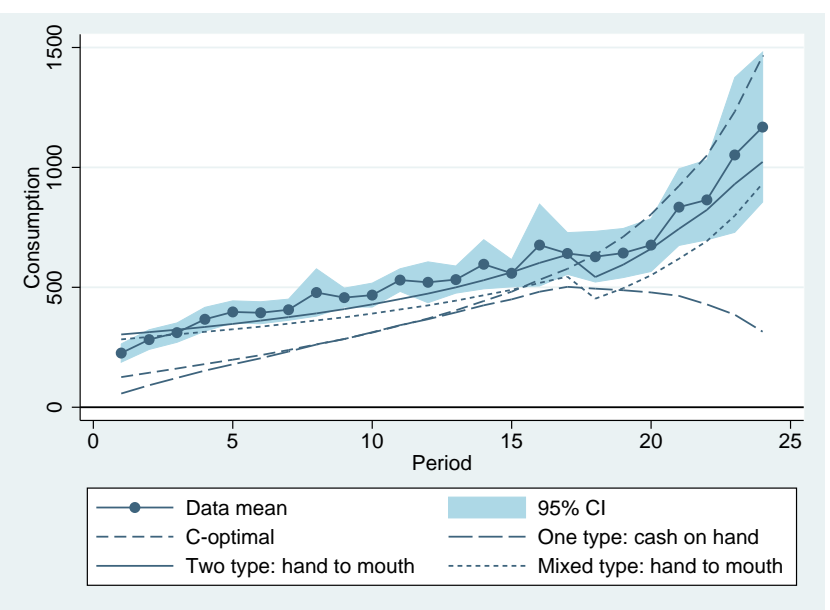

(a) $\mathrm{T} 1$

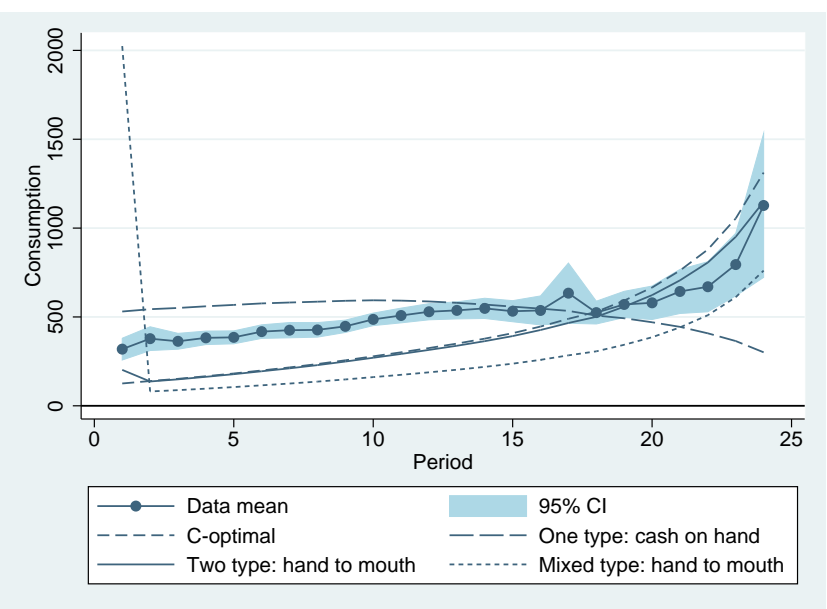

(c) T3

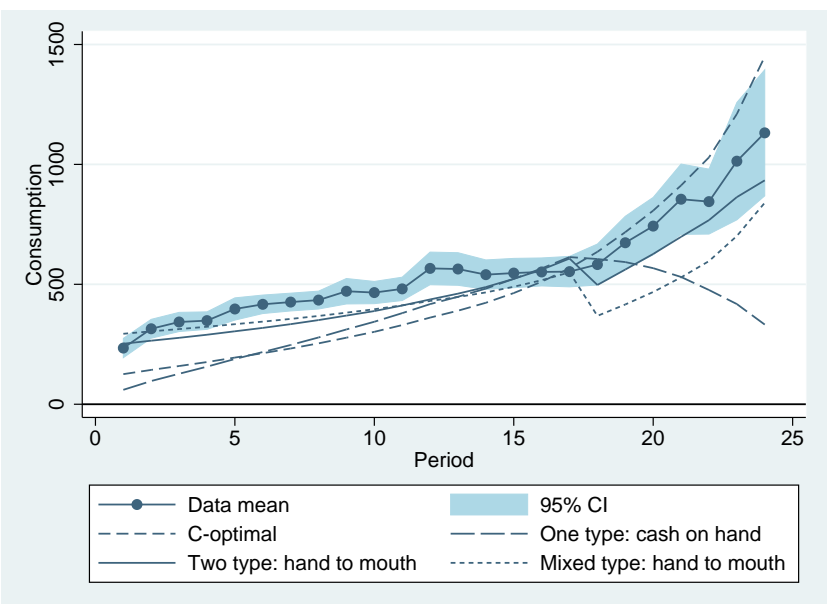

(b) $\mathrm{T} 2$

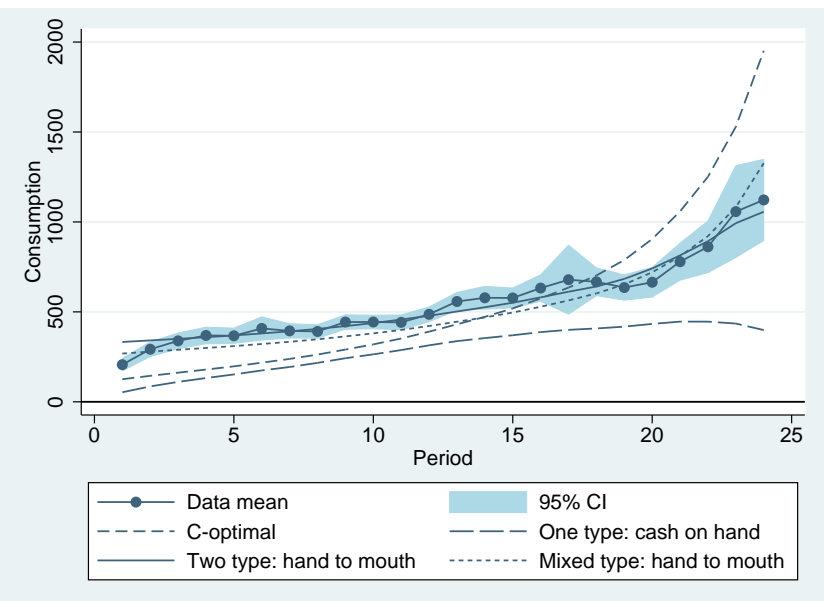

(d) $\mathrm{T} 4$

Figure 7: Fitness of selective models across the life cycle

This two-type model with hand to mouth consumers can also explain the over-andunder consumption pattern documented earlier. Given the presence of type 1 subjectshand to mouth consumers - when endowments are greater than the conditionally optimal consumption amount in the early periods of life, the average amount of consumption is greater than the conditionally optimal amount; when endowments are smaller than the conditionally optimal consumption amount in later periods of life, the average amount of consumption is smaller than the conditionally optimal amount. 


\section{Discussion of the Two-Type Model}

\subsection{Empirical Application}

The two-type model with hand to mouth consumers has been applied to solve issues in the real world. First, Campbell and Mankiw (1989) argue that a two-type model with the population approximately equally split between rational and hand to mouth consumers explains well the volatility in aggregate quarterly consumption. In our experiment, we find that a similar two-type model also explains well individual micro-level consumption decisions. Moreover, for T1, the treatment that most closely approximates the actual replacement of earned income upon retirement from social security benefits, the estimated share of type 1 agents is $47.5 \%$, close to the 50-50 division used by Campbell and Mankiw (1989).

Second, the two-type model has also been used by Central Banks as part of their economic forecasting models. For instance, the Central Organising Model for Projection Analysis and Scenario Simulation (COMPASS) developed by the Bank of England assumes that the economy is composed of two-types of agents - with 30 percent hand to mouth consumers and 70 percent rational consumers (Burgess et al., 2013).

Finally, the two-type model can also explain the success of a default option and automatic escalator for defined contribution retirement plans in affecting actual saving decisions. ${ }^{11}$ Some subjects in our experiment behave like a hand to mouth consumer simply because it is hard to solve the intertemporal allocation problem and so they adopt a rule of thumb of consuming endowments in each period. This behavioral deviation from rational choice theory helps explain why interventions that reduces take-home pay may be effective in increasing the saving rate. In the real world, in addition to the computational challenge of solving intertemporal allocation problems, individuals also face self-control problems. For instance they need to resist the temptation to consume more today, or the temptation to procrastinate

\footnotetext{
${ }^{11}$ For example, see Thaler and Benartzi (2004) and Chetty et al. (2014).
} 
on decisions to save more to a later date. It is likely that the self-control problem faced by real world individuals makes the strategy to consume take-home pay for each period even more appealing than observed in our experiment.

\subsection{Share of Subjects Adopting the Conditionally Optimal Path}

In Section 4, we find that subjects assigned to T4 (the constant endowment treatment) on average have greater lifetime utility and deviate less from the rational choice model predictions than subjects assigned to the other three treatments. This finding, however, does not imply that subjects assigned to T4 are more likely to adopt the conditionally optimal path than subjects assigned to the other three treatments, since T4 has the smallest RMSD between endowments and the conditionally optimal consumption path when the strategy of consuming endowments each period is adopted. ${ }^{12}$

To understand how the assignment of endowment profiles (our treatments) affects subjects' tendency to behave like a C-optimal type, we conduct the following three step analysis. First, we calculate the RMSD of consumption in periods 1-24 from the conditionally optimal level for each subject and sequence pair. Second, we classify a subject-sequence pair to be C-optimal if the RMSD is smaller than 80 percent of 233.6, which is the RMSD between consuming the endowment profile in T4 and the associated conditionally optimal consumption amount. We choose 80 percent as the threshold, because we do not want to classify those subjects in T4 who consume sufficiently close to their endowment level but have a RMSD slightly smaller than 233.6 as being C-optimal types.

Finally, we estimate the following equation:

$$
y_{i s t}=\beta_{1} \mathcal{I}_{t=1}+\beta_{2} \mathcal{I}_{t=2}+\beta_{3} \mathcal{I}_{t=3}+\beta_{4} \mathcal{I}_{t=4}+\beta_{5} \mathcal{I}_{s=2}+\beta_{6} \mathcal{I}_{s=3}+\beta_{7} \mathcal{I}_{s=4}+\epsilon_{i s t}
$$

\footnotetext{
${ }^{12}$ The RMSD is 290.3 for T1, 339.0 for T2, 923.1 for T3, and 233.6 for T4.
} 
where $y_{i s t}$ is an indicator variable equal to 1 if subject $i$ in sequence $s$ of treatment $t$ is classified as $\mathrm{C}$-optimal, and 0 otherwise; $\mathcal{I}$ is an indicator function that takes the value 1 if the subscript condition is true and 0 otherwise; $\epsilon_{i s t}$ is an error term. To account for the possible serial correlation between sequences within subjects, standard errors are clustered at the subject level. The coefficients of interest are $\beta_{1}-\beta_{4}$, which measure the share of subjects adopting the $\mathrm{C}$-optimal path in the first sequence and $\beta_{6}-\beta_{8}$ which measure the average difference from sequence 1 . The specification does not include a constant term, since we want to report the share of C-optimal types for each treatment and the constant term is collinear with the set of treatment dummies.

Table 8 reports the estimated treatment coefficients (shares) in lines 1-4 and sequence coefficients in lines 5-7.13 As Table 8 reveals, the treatment assignment affects the share of subjects classified as C-optimal, with the share of C-optimal types following the ranking $\mathrm{T} 2>\mathrm{T} 1>\mathrm{T} 3>\mathrm{T} 4$. In particular, a one-sided $t$-test shows that the share of the C-Optimal types in T4 is even smaller than that of T1 and T2 at the 5 percent level of significance, which suggests that flattening out the lifecycle endowment process (as in T4) makes subjects less likely to exert effort to solve the intertemporal allocation problem and to consume close to the conditionally optimal level.

The observed differences in the share of C-optimal types across treatments is not explained by differences in the stakes of the game, although subjects assigned to T4 face the smallest difference between the maximum earnings and earnings obtained by simply converting endowments in each period (see Table 1). There are two reasons why the stakes don't seem to matter for the share of C-optimal types. First, the information on final earnings is not readily available to subjects. To obtain that information, subjects must calculate the per period earnings associated with each strategy and sum these per period earnings up over the 25 periods of a lifecycle (sequence). Second, suppose that subjects "act as if" they can

\footnotetext{
${ }^{13}$ We also estimate this equation using a Probit model, and find similar results.
} 
Table 8: Effect of treatments and sequences on the share of subjects behaving like C-optimal types

\begin{tabular}{cccccc}
\hline \hline & $\begin{array}{c}\text { Coef. } \\
(1)\end{array}$ & $\begin{array}{c}\text { S.E. } \\
(2)\end{array}$ & $\begin{array}{c}\text { T2 } \\
(3)\end{array}$ & $\begin{array}{c}\text { T3 } \\
(4)\end{array}$ & $\begin{array}{c}\text { T4 } \\
(5)\end{array}$ \\
\hline T1 & 0.07 & 0.03 & $<$ & $>$ & $>^{* *}$ \\
T2 & 0.09 & 0.04 & & $>$ & $>^{* *}$ \\
T3 & 0.03 & 0.03 & & & $>$ \\
T4 & 0.00 & 0.02 & & & \\
\hline S2 & 0.02 & 0.03 & & & \\
S3 & 0.07 & 0.03 & & & \\
S4 & 0.09 & 0.03 & & & \\
\hline \hline
\end{tabular}

Note: Column (1) reports the coefficients and Column (2) reports standard errors. Columns (3)-(5) report the sign of the difference in coefficients between treatments and its significance $\left(* * *>0.01,{ }^{* *}>0.05, *>0.1\right)$ using a one-sided t-test. < indicates the coefficient of the row treatment is less than that of the column treatment, and $>$ indicates the opposite.

calculate the stakes. In that case, if subjects choose to be more like optimizing types when the stakes are higher, then the share of C-optimal types should be greatest in T3, and this is not the case.

We further find that the share of C-optimal types in S3 and S4 is statistically greater than that in S1 at the one percent level of significance. The later finding suggests that if repetition of the life-cycle planning problem were allowed, subjects could learn from their past experiences and behave more like the C-optimal type in future lifetimes.

As a robustness check, in Table A6 of Appendix B, we present results for alternative thresholds: 100 percent, 95 percent, 90 percent, 85 percent, and 75 percent of 233.6. In these alternative specifications, we always observe that the share of C-optimal types in $\mathrm{T} 4$ is smaller than in T1 or T2, except for one case where the threshold is taken to be 100 percent of the RMSD. 


\section{Conclusions}

The construction of a behavioral model validated using experimental data is a necessary first step in understanding how individuals are likely to respond to changes in social security and other retirement savings vehicles. In this paper we have gathered experimental evidence on lifecycle consumption and saving decisions over differing income profiles and developed a behavioral model that provides a good fit to the experimental data. Importantly, this model is also the one that provides a good fit to aggregate macro-level time series data on consumption (Campbell and Mankiw, 1989) and is used in Central Bank forecasting models (Burgess et al., 2013). We think that an obvious next step is to assess how well our two-type model matches features of the life-cycle and cross-sectional data on individual household consumption and asset accumulation, and to what extent the inclusion of hand to mouth consumers affects the welfare interpretation of social security programs in a theoretical framework. In addition, our experiment can be extended along two dimensions. First, one could introduce survival risks and health spending shocks to the retirement phase and examine the impact of these innovations on consumption and saving decisions. Second, it is possible that the pattern of over-and-under consumption is a result of the sequential nature of consumption and saving decisions. One could test this hypothesis by examining how individuals would make simultaneous allocations among different types of goods $\left(c_{i p}, p=\right.$ $1,2, \ldots, P)$ that are valued in the same way $\left(u\left(c_{i p}\right)\right)$ but are sold at different prices $\left(p_{i p}=\right.$ $\frac{1}{(1+r)^{p-1}}$ ). Any difference between the simultaneous allocation and the sequential allocation should be attributed to the behavioral bias associated with the time dimension. We leave these extensions to future research.

\section{References}

Akerlof, George A, "Procrastination and obedience," The American Economic Review, 1991, 81 (2), 1-19.

Ameriks, John, Joseph S Briggs, Andrew Caplin, Matthew D Shapiro, and Christopher Tonetti, "Long-term care utility and late in life saving," NBER Working Paper 2015. 
Ballinger, T Parker, Eric Hudson, Leonie Karkoviata, and Nathaniel T Wilcox, "Saving behavior and cognitive abilities," Experimental Economics, 2011, 14 (3), 349-374.

_ , Michael G Palumbo, and Nathaniel T Wilcox, "Precautionary saving and social learning across generations: An experiment," The Economic Journal, 2003, 113 (490), 920-947.

Brown, Alexander L, Zhikang Eric Chua, and Colin Camerer, "Learning and visceral temptation in dynamic savings experiments," Quarterly Journal of Economics, 2009, 124 (1), 197-231.

Brown, Jeffrey R, Arie Kapteyn, and Olivia S Mitchell, "Framing and claiming: How informationframing affects expected Social Security claiming behavior," Technical Report 12016.

_ , _, Erzo FP Luttmer, and Olivia S Mitchell, "Cognitive constraints on valuing annuities," NBER Working Paper 2013.

Burgess, Stephen, Emilio Fernandez-Corugedo, Charlotta Groth, Richard Harrison, Francesca Monti, Konstantinos Theodoridis, Matt Waldron et al., "The Bank of Englands forecasting platform: COMPASS, MAPS, EASE and the suite of models," Bank of England Working Paper 4712013.

Campbell, John Y and N Gregory Mankiw, "Consumption, income and interest rates: Reinterpreting the time series evidence," in "NBER Macroeconomics Annual 1989, Volume 4," MIT Press, 1989, pp. 185246.

Carbone, Enrica, "Understanding intertemporal choices," Applied Economics, 2006, 38 (8), 889-898.

- and John D Hey, "The effect of unemployment on consumption: an experimental analysis," The Economic Journal, 2004, 114 (497), 660-683.

- and John Duffy, "Lifecycle consumption plans, social learning and external habits: Experimental evidence," Journal of Economic Behavior \& Organization, 2014, 106, 413-427.

Carroll, Christopher D, "A theory of the consumption function, with and without liquidity constraints," Journal of Economic Perspectives, 2001, pp. 23-45.

Chetty, Raj, "A new method of estimating risk aversion," The American Economic Review, 2006, pp. 18211834.

_, John N Friedman, Søren Leth-Petersen, Torben Heien Nielsen, and Tore Olsen, "Active vs. passive decisions and crowd-out in retirement savings accounts: Evidence from Denmark," The Quarterly Journal of Economics, 2014, 129 (3), 1141-1219.

De Nardi, Mariacristina, Eric French, and John Bailey Jones, "Why do the elderly save? The role of medical expenses," Journal of Political Economy, 2010, 118 (1), 39-75.

Diamond, Peter A, "A framework for social security analysis," Journal of Public Economics, 1977, 8 (3), $275-298$.

Fehr, Ernst and Peter K Zych, "Do addicts behave rationally?," The Scandinavian Journal of Economics, 1998, $100(3), 643-661$.

_ and _, "Intertemporal choice under habit formation," Handbook of Experimental Economics Results, 2008, 1, 923-928.

Feldstein, Martin, "The optimal level of social security benefits," The Quarterly Journal of Economics, $1985,100(2), 303-320$. 
_ , "Structural reform of social security," Journal of Economic Perspectives, 2005, 19 (2), 33-55.

Feltovich, Nick and Ourega-Zoé Ejebu, "Do positional goods inhibit saving? Evidence from a life-cycle experiment," Journal of Economic Behavior 83 Organization, 2014, 107, 440-454.

Friedman, Milton, A theory of the consumption, Princeton University Press Princeton, NJ, 1957.

Hurd, Michael D et al., "Mortality risk and bequests," Econometrica, 1989, 57 (4), 779-813.

Johnson, Stephen, Laurence J Kotlikoff, and William Samuelson, "Can people compute? An experimental test of the life cycle consumption model," in "Essays on Saving, Bequests, Altruism, and Life-cycle Planning," MIT Press, 2001, pp. 335-386.

Kahneman, Daniel, Thinking, fast and slow, Macmillan, 2011.

Koehler, Derek J, Jesse Langstaff, and Wu-Qi Liu, "A simulated financial savings task for studying consumption and retirement decision making," Journal of Economic Psychology, 2015, 46, 89-97.

Kopecky, Karen A. Kopecky and Tatyana Koreshkova, "The impact of medical and nursing home expenses on savings," American Economic Journal: Macroeconomics, 2014, 6 (3), 29-72.

Kotlikoff, Laurence J, Avia Spivak, and Lawrence H Summers, "The adequacy of savings," The American Economic Review, 1982, 72 (5), 1056-1069.

_ , Lawrence H Summers et al., "The role of intergenerational transfers in aggregate capital accumulation," Journal of Political Economy, 1981, 89 (4), 706-32.

Laibson, David, "Golden eggs and hyperbolic discounting," The Quarterly Journal of Economics, 1997, pp. $443-477$.

Levy, Matthew and Joshua Tasoff, "Exponential-Growth bias and lifecycle consumption," Journal of the European Economic Association, 2015.

Levy, Matthew R and Joshua Tasoff, "Exponential-Growth bias in experimental consumption decisions," SSRN Working Paper 2015.

Liebman, Jeffrey B, Erzo FP Luttmer et al., "Would people behave differently if they better understood social security? Evidence from a field experiment.," American Economic Journal: Economic Policy, 2015, $7(1), 275-99$.

Loewenstein, George and Drazen Prelec, "Anomalies in intertemporal choice: Evidence and an interpretation," The Quarterly Journal of Economics, 1992, pp. 573-597.

Mankiw, N Gregory, "The savers-spenders theory of fiscal policy," American Economic Review, 2000, 90 (2), 120-125.

Meissner, Thomas, "Intertemporal consumption and debt aversion: an experimental study," Experimental Economics, 2014, pp. 1-18.

— and Davud Rostam-Afschar, "Do tax cuts increase consumption? An experimental test of Ricardian Equivalence," Working Paper 2014.

Modigliani, Franco and Richard Brumberg, "Utility analysis and the consumption function: An interpretation of cross-section data," Post-Keynesian Economics, 1954, 1. 
Munnell, Alicia H, Jean-Pierre Aubry, Josh Hurwitz et al., "How sensitive is public pension funding to investment returns," CRR Working Paper 2013.

Nardi, Mariacristina De, "Wealth inequality and intergenerational links," The Review of Economic Studies, 2004, 71 (3), 743-768.

O'Donoghue, Ted and Matthew Rabin, "Doing it now or later," American Economic Review, 1999, pp. $103-124$.

Shefrin, Hersh M and Richard H Thaler, "The behavioral life-cycle hypothesis," Economic Inquiry, 1988, 26 (4), 609-643.

Social Security Administration, "The 2016 OASDI Trustees Report," Government Report 2016.

Thaler, Richard $\mathbf{H}$ and Shlomo Benartzi, "Save more tomorrow: Using behavioral economics to increase employee saving," Journal of Political Economy, 2004, 112 (S1), S164-S187. 


\section{Appendix For Online Publication}

\section{A Sample Screenshots and Experimental Instructions}

In this section, we include some sample screenshots from our experiment and the instructions used for the treatment order T1-T2. Instructions for the other treatment orders are similar to those reproduced here except that the distribution of endowments is different.

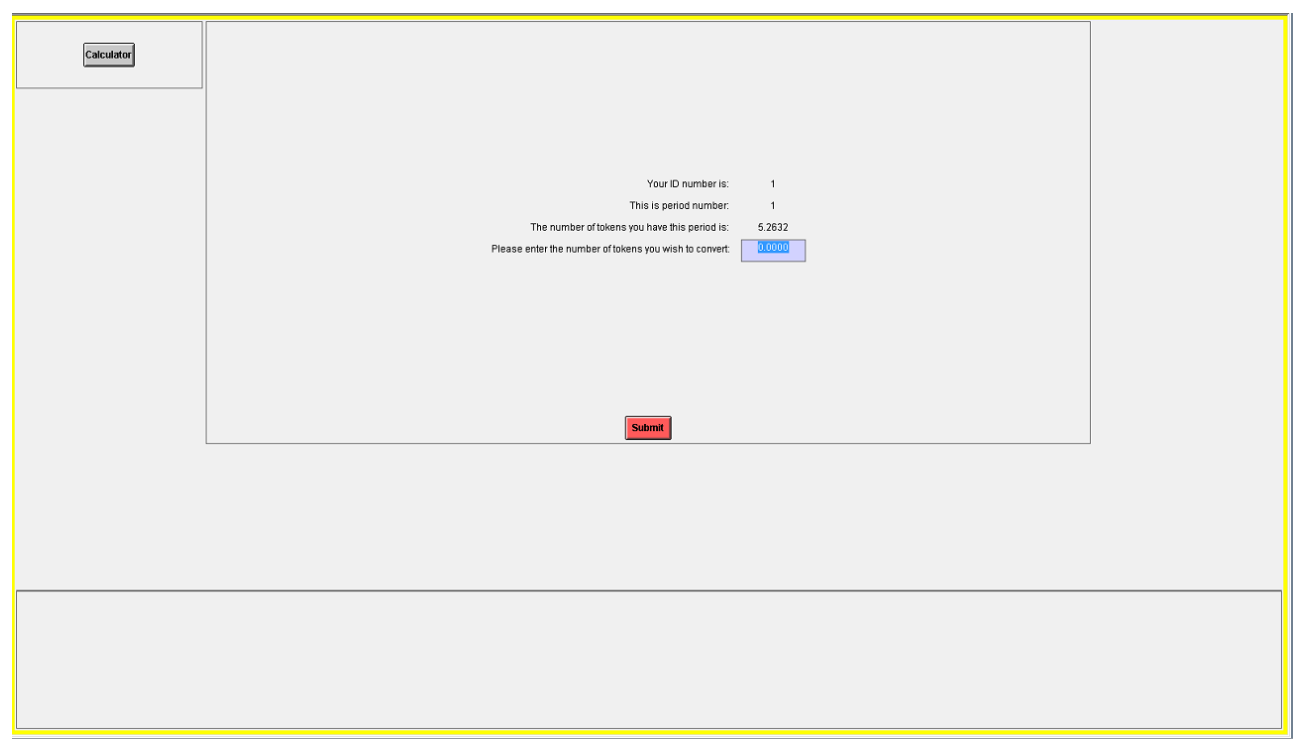

(a) Decision

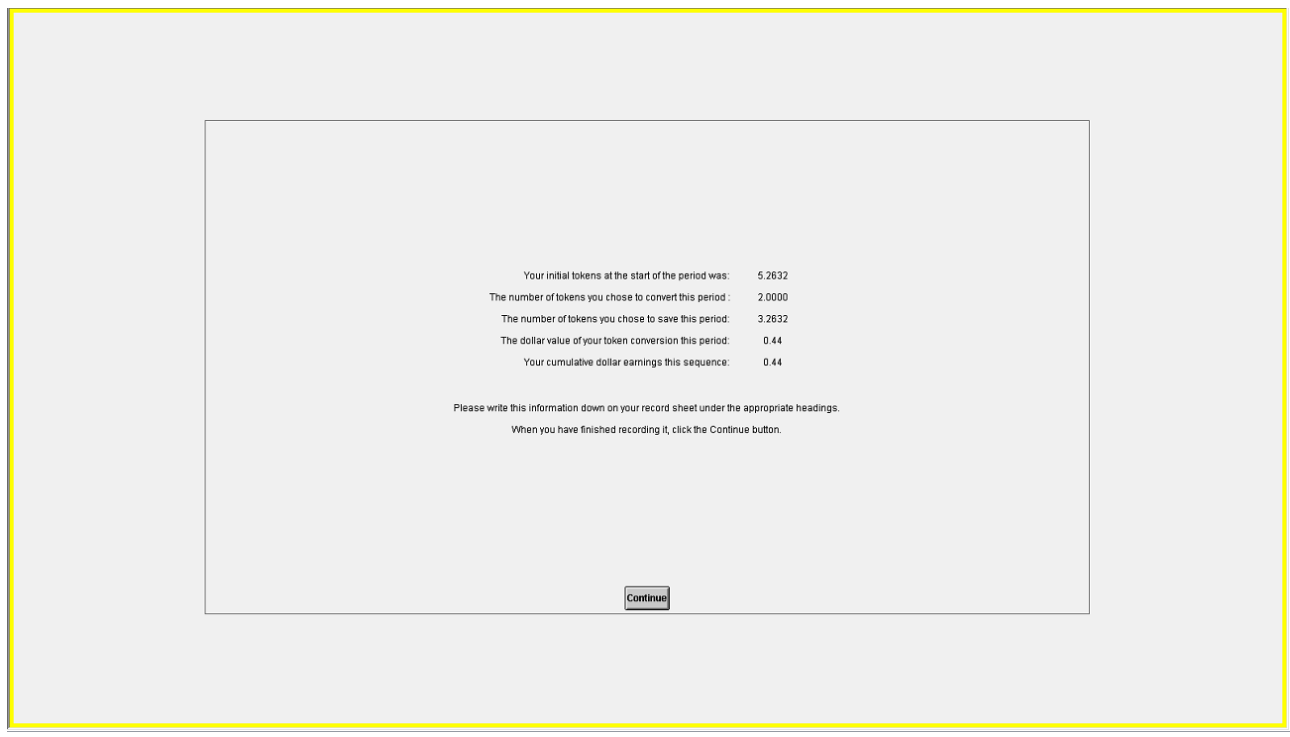

(b) Results

Figure A1: Screenshots from the experiment 


\section{Instructions}

\section{$\underline{\text { Overview }}$}

Welcome to this experiment in the economics of decision-making. You are guaranteed $\$ 7$ for showing up and completing this experiment. These instructions explain how you can earn additional amounts of money from the decisions that you make in today's session. There is no talking for the duration of this session. Please silence all mobile devices. If you have a question, please raise your hand and your question will be answered in private.

Today's session consists of two parts. These instructions are for the first part. After completing the first part of the experiment, you will receive instructions for the second part. At the end of the second part you will be paid your earnings from both parts together with your $\$ 7$ show-up payment in cash and in private.

\section{$\underline{\text { Part One Instructions }}$}

The first part of today's experiment involves two "sequences". Each sequence consists of 25 "periods" of decision-making. At the start of each period you are endowed with a certain number of "tokens." The exact number of tokens given to you in each of the 25 periods of a sequence is shown in Table 1 and is graphed in Figure 1. Please take a moment to look at this sequence of tokens that you will be given. Notice that in some periods, you are given a large number of tokens while in other periods you are given a small number of tokens. The number of tokens you are given each period will also be indicated on your computer screen. In addition to the tokens you are given each period you may have additional tokens that you have saved from prior periods which earn interest in terms of additional tokens as explained below. After viewing the total number of tokens you have available --the amount you are given for the period and your tokens from savings and interest-- you must decide how many of these tokens you wish to convert into money for the period. You can convert any number of tokens from 0 up to the maximum total tokens you have available in each period, and you can choose to convert fractions of tokens up to four decimal places. If the $25^{\text {th }}$ period has not yet been reached, then any remaining tokens that you do not convert into money will be saved for your use in later periods, and these savings will earn interest in the form of additional tokens available to you in these later periods as explained in more detail below. In the $25^{\text {th }}$ period, any tokens that you do not convert into money will become worthless.

Your earnings for each period depend on the number of tokens that you convert into money in that period and are shown in Table 2 and graphed in Figure 2. Notice several things. First, only some token amounts that you may wish to convert into money are shown, e.g., 0, $100, \ldots, 500, \ldots 2000, \ldots 10,000$. The precise formula used to determine your earnings (in dollars) from converting tokens into money is given at the bottom of Table 2. Second, notice that the more tokens you convert, the greater are your money earnings for that period. Finally, notice also that the money you earn from converting tokens is proportionally diminishing; the difference in 
your money earnings from converting 500 rather than 400 tokens is larger than the difference in your money earnings from converting 1500 rather than 1400 tokens.

At the start of all 25 periods in a sequence you receive some number of tokens as reported in Table 1 and Figure 1. In addition, in periods 2,..25, you may have additional tokens available to you depending on whether you have saved any tokens in prior periods; in that case, you will also receive interest on those savings paid to you in additional tokens. Specifically, you will earn an interest rate of 10 percent per period, paid to you in additional tokens, at the start of the next period. Thus, if in this period you saved $S>0$ tokens, then at the start of the next period you would have $S+(S \times .10)$ (equivalently $(1.10) \times S)$ tokens available to you in addition to the tokens you receive at the start of each new period as given in Table 1. Table 3 shows how various token amounts saved $(\mathrm{S})$ in one period result in additional token amounts of $(1+.10) \times \mathrm{S}$ in the following period.

Thus at the start of every period you may have some tokens available to you. Your decision screen will report this total available token number to you, breaking it down according to:

1) Token endowment this period: as given in Table 1.

2) Tokens saved from the last period: $S$

3) Interest earned on tokens saved from last period savings: $\mathrm{S} \times 10$

The total tokens you have available to convert into money or to save in the current period will be the sum of these three numbers.

\section{$\underline{\text { Your Decision }}$}

Type the number of tokens you wish to convert into money (up to four decimal places) in the input box on your decision screen. You may refer to Table 2 and Figure 2 to understand how your token conversion decision determines your earnings, but you can also use the calculator on the top left part of this decision screen to determine how your token conversion decision will translate into money this period. Once you have entered your choice click the Submit button to confirm your choice. You can change your mind anytime prior to clicking the Submit button.

Once the first 25-period sequence is completed, you will begin playing a second 25-period sequence. The second sequence will be just like the first sequence in that you will again receive the same endowment of tokens in each of the 25 periods as indicated in Table 1 and Figure 1 and you will again make token conversion decisions each period as before. Table 2, Figure 2 and Table 3 will continue to apply for determining your money earnings and how saving decisions determine additional tokens.

$\underline{\text { Information }}$ 
Following the first period of a sequence, and after every period thereafter, you will be reminded of the total tokens you initially had available at the start of the period, your token conversion decision, your saved tokens, your money earnings for the period as well as your cumulative total money payoff for the current 25-period sequence. Please record this information on your Record Sheets under the appropriate headings. For your convenience, a complete history of this information will be provided at the bottom of your decision screen (following the first period of each sequence).

\section{Earnings}

After the second 25-period sequence has been completed, we will randomly select one of the two 25 -period sequences you played. Both sequences have an equal chance of being chosen. Your cumulative money earnings from the one chosen sequence will comprise your earnings for this first part of today's experiment.

Questions? Now is the time for questions. If you have a question, please raise your hand and the experimenter will answer your question in private. 


\section{Quiz}

Before continuing on to the experiment, we ask that you complete the following quiz for the part one instructions. In answering these questions, you may consult the instructions, tables and figures. Your performance on this quiz does not affect your payoff in any way. Write or circle your answers to the quiz questions as indicated. Do not put your name on this quiz. If any questions are answered incorrectly, we will go over the relevant part of the instructions again.

1. In part one you will participate in sequences. Each sequence consists of periods.

2. Suppose it is period 1. What is the maximum number of tokens that you can convert into money this period? . What is the minimum number of tokens you can convert into money this period?

3. Suppose it is period 10. What is your endowment of tokens in this period? If, in period 9 your savings was 1,000 tokens, how many total tokens, including savings, interest earnings and your endowment of tokens for period 10 will you be able to convert into money in period 10 ?

4. Suppose it is period 20. What is your endowment of tokens in this period? If, in period 19 your savings was 7,000 tokens, how many total tokens, including savings, interest earnings and your endowment of tokens for period 20 will you be able to convert into money in period 20 ?

5. Suppose it is period 25. If you choose to save some of your tokens in period 25, will they have any future value to you? Circle one Yes No.

6. True or false: Your earnings will depend on your cumulative money earnings from one of the two 25-period sequences you play, but you will not know which sequence will be chosen until the end of the session. Circle one: True False 


\begin{tabular}{|r|r|}
\hline \multicolumn{2}{|c|}{ Table 1: Endowment of Tokens } \\
\hline Period & Tokens You are Given \\
\hline 1 & 500 \\
\hline 2 & 500 \\
\hline 3 & 500 \\
\hline 4 & 500 \\
\hline 5 & 500 \\
\hline 6 & 500 \\
\hline 7 & 500 \\
\hline 8 & 500 \\
\hline 9 & 500 \\
\hline 10 & 500 \\
\hline 11 & 500 \\
\hline 12 & 500 \\
\hline 13 & 500 \\
\hline 14 & 500 \\
\hline 15 & 500 \\
\hline 16 & 500 \\
\hline 17 & 500 \\
\hline 18 & 200 \\
\hline 19 & 200 \\
\hline 20 & 200 \\
\hline 21 & 200 \\
\hline 22 & 200 \\
\hline 23 & 200 \\
\hline 24 & 200 \\
\hline 25 & 200 \\
\hline
\end{tabular}




\begin{tabular}{|c|c|}
\hline $\begin{array}{l}\text { Tokens } \\
\text { Converted }\end{array}$ & $\begin{array}{r}\text { Money Earnings } \\
\text { for the Period }\end{array}$ \\
\hline 0 & 0.00 \\
\hline 100 & 0.14 \\
\hline 200 & 0.22 \\
\hline 300 & 0.28 \\
\hline 400 & 0.32 \\
\hline 500 & 0.36 \\
\hline 600 & 0.39 \\
\hline 700 & 0.42 \\
\hline 800 & 0.44 \\
\hline 900 & 0.46 \\
\hline 1000 & 0.48 \\
\hline 1100 & 0.50 \\
\hline 1200 & 0.51 \\
\hline 1300 & 0.53 \\
\hline 1400 & 0.54 \\
\hline 1500 & 0.55 \\
\hline 1600 & 0.57 \\
\hline 1700 & 0.58 \\
\hline 1800 & 0.59 \\
\hline 1900 & 0.60 \\
\hline 2000 & 0.61 \\
\hline 3000 & 0.69 \\
\hline 4000 & 0.74 \\
\hline 5000 & 0.79 \\
\hline 6000 & 0.82 \\
\hline 7000 & 0.85 \\
\hline 8000 & 0.88 \\
\hline 9000 & 0.90 \\
\hline 10000 & 0.92 \\
\hline
\end{tabular}

\begin{tabular}{|c|c|c|}
\hline \multicolumn{3}{|c|}{ Table 3: Savings and Interest } \\
\hline $\begin{array}{l}\text { Tokens } \\
\text { Saved }\end{array}$ & $\begin{array}{l}\text { Interest Earned } \\
\text { in Tokens }\end{array}$ & $\begin{array}{l}\text { Savings+Interest } \\
\text { in Tokens }\end{array}$ \\
\hline 0 & 0 & 0 \\
\hline 100 & 10 & 110 \\
\hline 200 & 20 & 220 \\
\hline 300 & 30 & 330 \\
\hline 400 & 40 & 440 \\
\hline 500 & 50 & 550 \\
\hline 600 & 60 & 660 \\
\hline 700 & 70 & 770 \\
\hline 800 & 80 & 880 \\
\hline 900 & 90 & 990 \\
\hline 1000 & 100 & 1100 \\
\hline 1100 & 110 & 1210 \\
\hline 1200 & 120 & 1320 \\
\hline 1300 & 130 & 1430 \\
\hline 1400 & 140 & 1540 \\
\hline 1500 & 150 & 1650 \\
\hline 1600 & 160 & 1760 \\
\hline 1700 & 170 & 1870 \\
\hline 1800 & 180 & 1980 \\
\hline 1900 & 190 & 2090 \\
\hline 2000 & 200 & 2200 \\
\hline 3000 & 300 & 3300 \\
\hline 4000 & 400 & 4400 \\
\hline 5000 & 500 & 5500 \\
\hline 6000 & 600 & 6600 \\
\hline 7000 & 700 & 7700 \\
\hline 8000 & 800 & 8800 \\
\hline 9000 & 900 & 9900 \\
\hline 10000 & 1000 & 11000 \\
\hline
\end{tabular}

Money $=\$ 0.2 * \ln (0.01 *$ Tokens Converted +1$)$

Interest $($ in Tokens $)=0.1 *$ Tokens Saved 


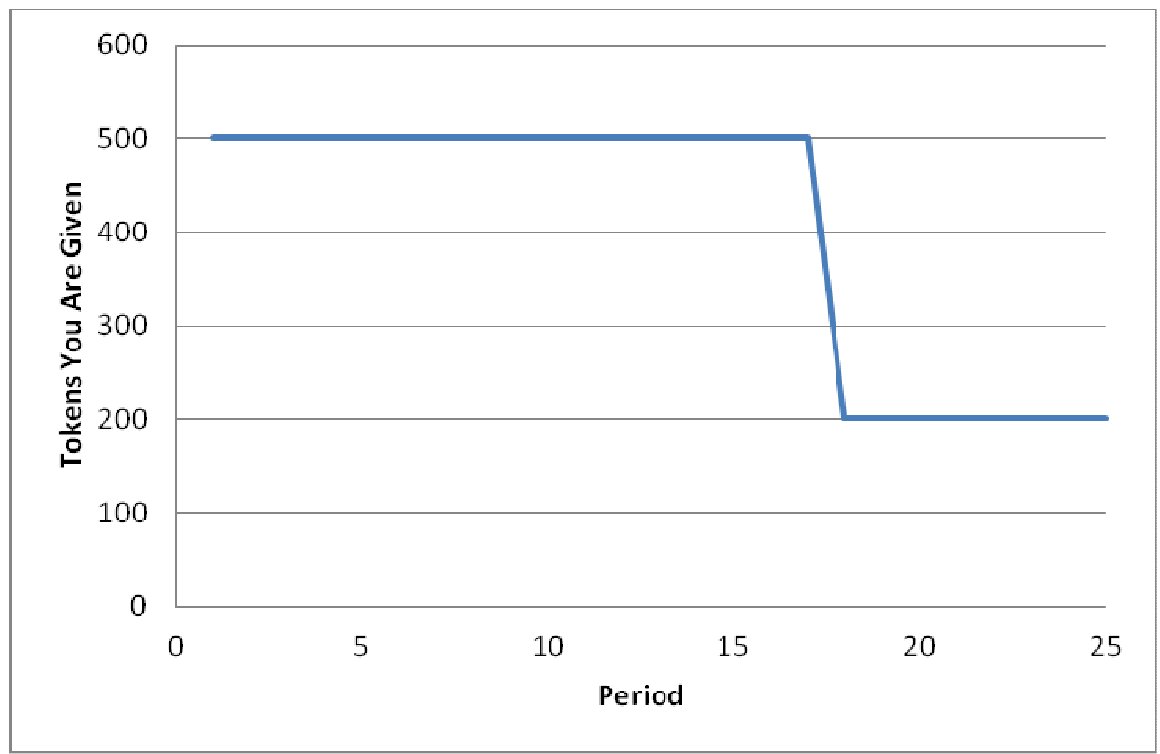

Figure 1: Token You are Given by Period

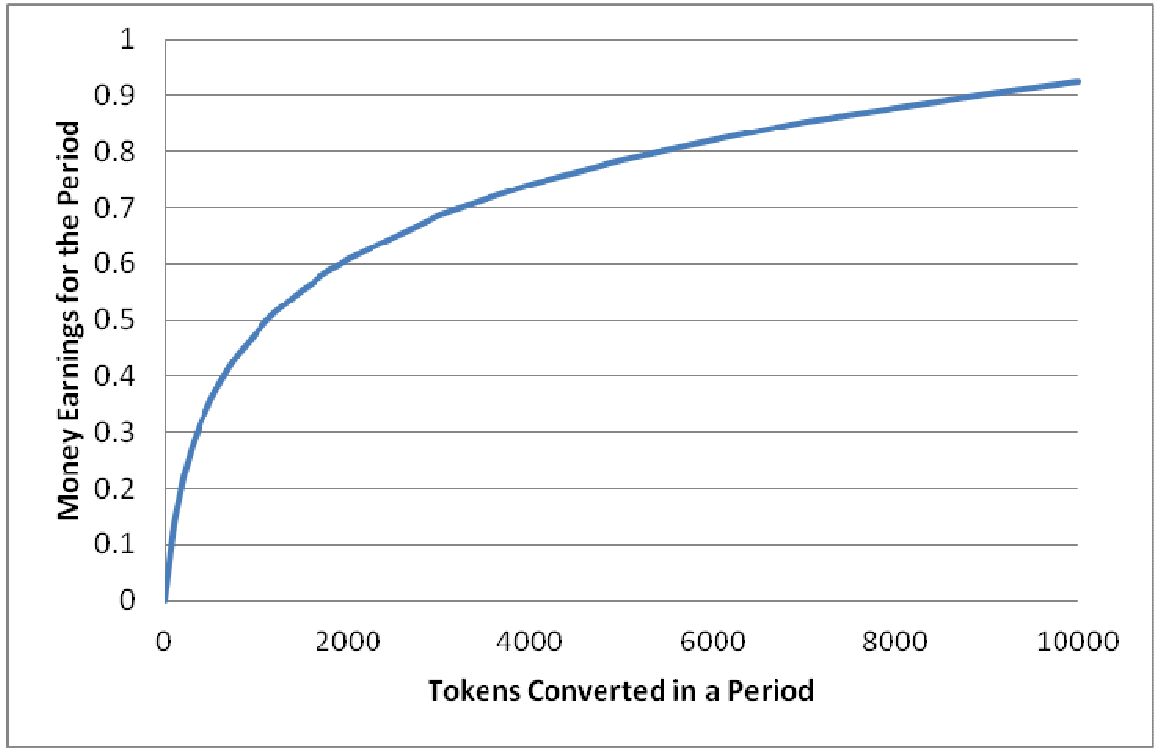

Figure 2: Token Conversions and Money Earned 
Record Sheet Part 1 Player ID

Age _ Sex(Circle) F $\quad$ M

\begin{tabular}{|c|c|c|c|c|c|c|}
\hline Sequence & Period & $\begin{array}{l}\text { Initial Total } \\
\text { Tokens at the } \\
\text { Start of this } \\
\text { Period }\end{array}$ & $\begin{array}{l}\text { Number of } \\
\text { Tokens You } \\
\text { Converted } \\
\text { this Period } \\
\end{array}$ & $\begin{array}{l}\text { Number of } \\
\text { Tokens You } \\
\text { Saved this } \\
\text { Period }\end{array}$ & $\begin{array}{l}\text { Money } \\
\text { Earned for } \\
\text { this Period }\end{array}$ & $\begin{array}{l}\text { Cumulative } \\
\text { Money } \\
\text { Earnings as } \\
\text { of this Period }\end{array}$ \\
\hline 1 & 1 & & & & & \\
\hline 1 & 2 & & & & & \\
\hline 1 & 3 & & & & & \\
\hline 1 & 4 & & & & & \\
\hline 1 & 5 & & & & & \\
\hline 1 & 6 & & & & & \\
\hline 1 & 7 & & & & & \\
\hline 1 & 8 & & & & & \\
\hline 1 & 9 & & & & & \\
\hline 1 & 10 & & & & & \\
\hline 1 & 11 & & & & & \\
\hline 1 & 12 & & & & & \\
\hline 1 & 13 & & & & & \\
\hline 1 & 14 & & & & & \\
\hline 1 & 15 & & & & & \\
\hline 1 & 16 & & & & & \\
\hline 1 & 17 & & & & & \\
\hline 1 & 18 & & & & & \\
\hline 1 & 19 & & & & & \\
\hline 1 & 20 & & & & & \\
\hline 1 & 21 & & & & & \\
\hline 1 & 22 & & & & & \\
\hline 1 & 23 & & & & & \\
\hline 1 & 24 & & & & & \\
\hline 1 & 25 & & & & & \\
\hline
\end{tabular}


Record Sheet Part 1 Player ID

Age _ Sex(Circle) F $\quad$ M

\begin{tabular}{|c|c|c|c|c|c|c|}
\hline Sequence & Period & $\begin{array}{l}\text { Initial Total } \\
\text { Tokens at the } \\
\text { Start of this } \\
\text { Period }\end{array}$ & $\begin{array}{l}\text { Number of } \\
\text { Tokens You } \\
\text { Converted } \\
\text { this Period }\end{array}$ & $\begin{array}{l}\text { Number of } \\
\text { Tokens You } \\
\text { Saved this } \\
\text { Period }\end{array}$ & $\begin{array}{l}\text { Money } \\
\text { Earned for } \\
\text { this Period }\end{array}$ & $\begin{array}{l}\text { Cumulative } \\
\text { Money } \\
\text { Earnings as } \\
\text { of this Period }\end{array}$ \\
\hline 2 & 1 & & & & & \\
\hline 2 & 2 & & & & & \\
\hline 2 & 3 & & & & & \\
\hline 2 & 4 & & & & & \\
\hline 2 & 5 & & & & & \\
\hline 2 & 6 & & & & & \\
\hline 2 & 7 & & & & & \\
\hline 2 & 8 & & & & & \\
\hline 2 & 9 & & & & & \\
\hline 2 & 10 & & & & & \\
\hline 2 & 11 & & & & & \\
\hline 2 & 12 & & & & & \\
\hline 2 & 13 & & & & & \\
\hline 2 & 14 & & & & & \\
\hline 2 & 15 & & & & & \\
\hline 2 & 16 & & & & & \\
\hline 2 & 17 & & & & & \\
\hline 2 & 18 & & & & & \\
\hline 2 & 19 & & & & & \\
\hline 2 & 20 & & & & & \\
\hline 2 & 21 & & & & & \\
\hline 2 & 22 & & & & & \\
\hline 2 & 23 & & & & & \\
\hline 2 & 24 & & & & & \\
\hline 2 & 25 & & & & & \\
\hline
\end{tabular}




\section{Instructions, Continued}

\section{$\underline{\text { Part Two Instructions }}$}

The second part of today's experiment is similar to the first part and involves two more 25period sequences of decision-making. At the start of each period you are again endowed with a certain number of tokens and must again decide how many of your total available tokens you wish to convert into money each period. The only difference from the first part is that in this second part of the experiment, the number of tokens given to you in each of the 25 periods of a sequence is different from before and is now shown in Table 4 and graphed in Figure 3. Please take a moment to look at this new sequence of token amounts. Notice that in some periods you are given a large number of tokens while in other periods you are given 0 tokens. The number of tokens you are given in each of the 25 periods will again be indicated on your computer screen. As in the first part, in addition to the tokens you are given each period you may have additional tokens that you have saved from prior periods which earn interest at the same rate of 10 percent as in the first part. After viewing the total number of tokens you have available -- the amount you are given for the period and your tokens from any prior period savings and interest-- you must decide how many of these tokens you wish to convert into money for the period. You can convert any number of tokens from 0 up to the maximum total tokens you have available for that period, and you can choose to convert fractions of tokens up to four decimal places. If the $25^{\text {th }}$ period has not yet been reached, then the remaining tokens that you do not convert into money will be saved for your use in later periods, and these savings will earn 10 percent interest per period in the form of additional tokens available to you next period just as in the first part. In the $25^{\text {th }}$ period, any tokens that you do not convert into money will become worthless.

The amounts of money you can earn from converting tokens each period is the same as in the first part and thus continues to be given by Table 2 for certain possible token conversion amounts and is graphed in Figure 2. (These are reprinted below). As before, a calculator is available on the top left side of your decision screen to help you determine how your token conversion decisions translate into money earnings each period. As noted above, the interest rate on savings remains the same at 10 percent per period, so that Table 3 (also reprinted below) continues to reveal how various token amounts saved this period earn interest for you in terms of additional tokens next period.

As in the first part you will complete two, 25-period sequences of decision-making. The second sequence will be just like the first sequence in that you will continue to receive the same endowment of tokens in each of the 25 periods as now indicated in the new Table 4 and you will make token conversion decisions each period just as before.

To reiterate, the only change from the first part is that the endowments of tokens that you are given in each of the 25 periods of each sequence in this second part of the experiment are different and are now given in the new Table 4. 


\section{$\underline{\text { Information }}$}

Following the first period of a sequence, and after every period thereafter, you will again be reminded of the total tokens you initially had available at the start of the period, your token conversion decision, your saved tokens, your money payoff for the period as well as your cumulative total money earnings for the current 25-period sequence. Please record this information on your Record Sheets under the appropriate headings. For your convenience, a complete history of this information will be provided at the bottom of your decision screen (following the first period of each sequence).

\section{Earnings}

After the second 25-period sequence has been completed, we will randomly select one of the two 25-period sequences you played. Both sequences have an equal chance of being chosen. Your cumulative money earnings from the one chosen sequence will comprise your earnings for this second part of today's experiment.

Following the completion of this second part, the experiment will be over. You will be paid your earnings from the first and second parts together with your \$7 show-up payment in cash and in private.

\section{Questions?}

Now is the time for questions. If you have a question, please raise your hand and the experimenter will answer your question in private. 


\begin{tabular}{|c|c|}
\hline Period & Tokens You are Given \\
\hline 1 & 526 \\
\hline 2 & 526 \\
\hline 3 & 526 \\
\hline 4 & 526 \\
\hline 5 & 526 \\
\hline 6 & 526 \\
\hline 7 & 526 \\
\hline 8 & 526 \\
\hline 9 & 526 \\
\hline 10 & 526 \\
\hline 11 & 526 \\
\hline 12 & 526 \\
\hline 13 & 526 \\
\hline 14 & 526 \\
\hline 15 & 526 \\
\hline 16 & 526 \\
\hline 17 & 526 \\
\hline 18 & 0 \\
\hline 19 & 0 \\
\hline 20 & 0 \\
\hline 21 & 0 \\
\hline 22 & 0 \\
\hline 23 & 0 \\
\hline 24 & 0 \\
\hline 25 & 0 \\
\hline
\end{tabular}




\begin{tabular}{|c|c|}
\hline $\begin{array}{l}\text { Tokens } \\
\text { Converted }\end{array}$ & $\begin{array}{r}\text { Money Earnings } \\
\text { for the Period }\end{array}$ \\
\hline 0 & 0.00 \\
\hline 100 & 0.14 \\
\hline 200 & 0.22 \\
\hline 300 & 0.28 \\
\hline 400 & 0.32 \\
\hline 500 & 0.36 \\
\hline 600 & 0.39 \\
\hline 700 & 0.42 \\
\hline 800 & 0.44 \\
\hline 900 & 0.46 \\
\hline 1000 & 0.48 \\
\hline 1100 & 0.50 \\
\hline 1200 & 0.51 \\
\hline 1300 & 0.53 \\
\hline 1400 & 0.54 \\
\hline 1500 & 0.55 \\
\hline 1600 & 0.57 \\
\hline 1700 & 0.58 \\
\hline 1800 & 0.59 \\
\hline 1900 & 0.60 \\
\hline 2000 & 0.61 \\
\hline 3000 & 0.69 \\
\hline 4000 & 0.74 \\
\hline 5000 & 0.79 \\
\hline 6000 & 0.82 \\
\hline 7000 & 0.85 \\
\hline 8000 & 0.88 \\
\hline 9000 & 0.90 \\
\hline 10000 & 0.92 \\
\hline
\end{tabular}

\begin{tabular}{|c|c|c|}
\hline \multicolumn{3}{|c|}{ Table 3: Savings and Interest } \\
\hline $\begin{array}{l}\text { Tokens } \\
\text { Saved }\end{array}$ & $\begin{array}{l}\text { Interest Earned } \\
\text { in Tokens }\end{array}$ & $\begin{array}{l}\text { Savings+Interest } \\
\text { in Tokens }\end{array}$ \\
\hline 0 & 0 & 0 \\
\hline 100 & 10 & 110 \\
\hline 200 & 20 & 220 \\
\hline 300 & 30 & 330 \\
\hline 400 & 40 & 440 \\
\hline 500 & 50 & 550 \\
\hline 600 & 60 & 660 \\
\hline 700 & 70 & 770 \\
\hline 800 & 80 & 880 \\
\hline 900 & 90 & 990 \\
\hline 1000 & 100 & 1100 \\
\hline 1100 & 110 & 1210 \\
\hline 1200 & 120 & 1320 \\
\hline 1300 & 130 & 1430 \\
\hline 1400 & 140 & 1540 \\
\hline 1500 & 150 & 1650 \\
\hline 1600 & 160 & 1760 \\
\hline 1700 & 170 & 1870 \\
\hline 1800 & 180 & 1980 \\
\hline 1900 & 190 & 2090 \\
\hline 2000 & 200 & 2200 \\
\hline 3000 & 300 & 3300 \\
\hline 4000 & 400 & 4400 \\
\hline 5000 & 500 & 5500 \\
\hline 6000 & 600 & 6600 \\
\hline 7000 & 700 & 7700 \\
\hline 8000 & 800 & 8800 \\
\hline 9000 & 900 & 9900 \\
\hline 10000 & 1000 & 11000 \\
\hline
\end{tabular}

Money $=\$ 0.2 * \ln (0.01 *$ Tokens Converted +1$)$

Interest $($ in Tokens $)=0.1 *$ Tokens Saved 


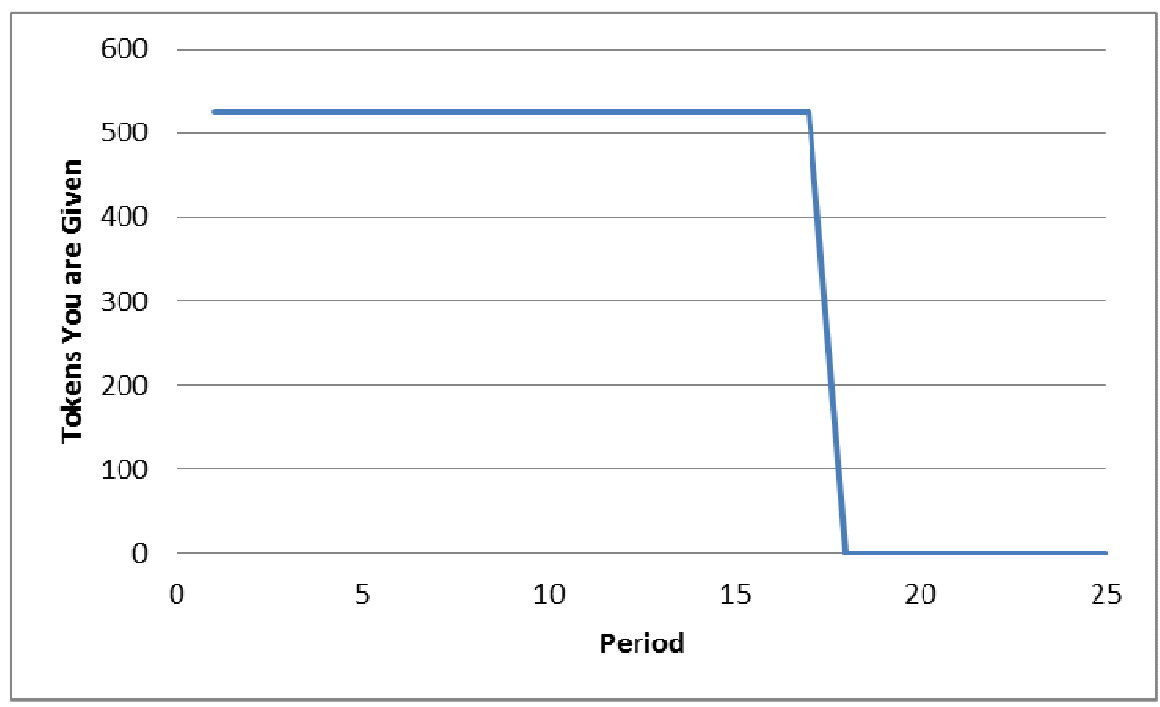

Figure 3: Token You are Given by Period

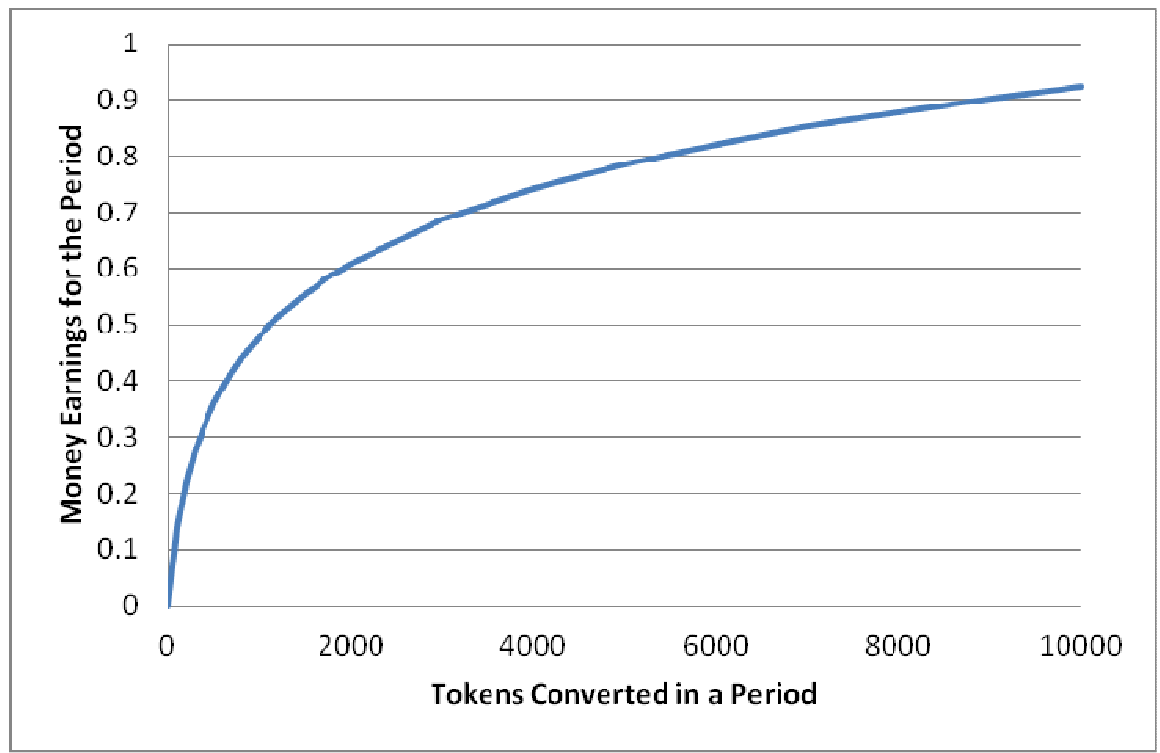

Figure 2: Token Conversions and Money Earned 
Record Sheet Part 2 Player ID

Age _ Sex(Circle) F M

\begin{tabular}{|c|c|c|c|c|c|c|}
\hline Sequence & Period & $\begin{array}{l}\text { Initial Total } \\
\text { Tokens at the } \\
\text { Start of this } \\
\text { Period }\end{array}$ & $\begin{array}{l}\text { Number of } \\
\text { Tokens You } \\
\text { Converted } \\
\text { this Period }\end{array}$ & $\begin{array}{l}\text { Number of } \\
\text { Tokens You } \\
\text { Saved this } \\
\text { Period }\end{array}$ & $\begin{array}{l}\text { Money } \\
\text { Earned for } \\
\text { this Period }\end{array}$ & $\begin{array}{l}\text { Cumulative } \\
\text { Money } \\
\text { Earnings as } \\
\text { of this Period }\end{array}$ \\
\hline 1 & 1 & & & & & \\
\hline 1 & 2 & & & & & \\
\hline 1 & 3 & & & & & \\
\hline 1 & 4 & & & & & \\
\hline 1 & 5 & & & & & \\
\hline 1 & 6 & & & & & \\
\hline 1 & 7 & & & & & \\
\hline 1 & 8 & & & & & \\
\hline 1 & 9 & & & & & \\
\hline 1 & 10 & & & & & \\
\hline 1 & 11 & & & & & \\
\hline 1 & 12 & & & & & \\
\hline 1 & 13 & & & & & \\
\hline 1 & 14 & & & & & \\
\hline 1 & 15 & & & & & \\
\hline 1 & 16 & & & & & \\
\hline 1 & 17 & & & & & \\
\hline 1 & 18 & & & & & \\
\hline 1 & 19 & & & & & \\
\hline 1 & 20 & & & & & \\
\hline 1 & 21 & & & & & \\
\hline 1 & 22 & & & & & \\
\hline 1 & 23 & & & & & \\
\hline 1 & 24 & & & & & \\
\hline 1 & 25 & & & & & \\
\hline
\end{tabular}


Record Sheet Part 2 Player ID

Age __ Sex(Circle) F $\quad$ M

\begin{tabular}{|c|c|c|c|c|c|c|}
\hline Sequence & Period & $\begin{array}{l}\text { Initial Total } \\
\text { Tokens at the } \\
\text { Start of this } \\
\text { Period }\end{array}$ & $\begin{array}{l}\text { Number of } \\
\text { Tokens You } \\
\text { Converted } \\
\text { this Period }\end{array}$ & $\begin{array}{l}\text { Number of } \\
\text { Tokens You } \\
\text { Saved this } \\
\text { Period }\end{array}$ & $\begin{array}{l}\text { Money } \\
\text { Earned for } \\
\text { this Period }\end{array}$ & $\begin{array}{l}\text { Cumulative } \\
\text { Money } \\
\text { Earnings as } \\
\text { of this Period }\end{array}$ \\
\hline 2 & 1 & & & & & \\
\hline 2 & 2 & & & & & \\
\hline 2 & 3 & & & & & \\
\hline 2 & 4 & & & & & \\
\hline 2 & 5 & & & & & \\
\hline 2 & 6 & & & & & \\
\hline 2 & 7 & & & & & \\
\hline 2 & 8 & & & & & \\
\hline 2 & 9 & & & & & \\
\hline 2 & 10 & & & & & \\
\hline 2 & 11 & & & & & \\
\hline 2 & 12 & & & & & \\
\hline 2 & 13 & & & & & \\
\hline 2 & 14 & & & & & \\
\hline 2 & 15 & & & & & \\
\hline 2 & 16 & & & & & \\
\hline 2 & 17 & & & & & \\
\hline 2 & 18 & & & & & \\
\hline 2 & 19 & & & & & \\
\hline 2 & 20 & & & & & \\
\hline 2 & 21 & & & & & \\
\hline 2 & 22 & & & & & \\
\hline 2 & 23 & & & & & \\
\hline 2 & 24 & & & & & \\
\hline 2 & 25 & & & & & \\
\hline
\end{tabular}




\section{B Additional Tables and Figures}

In this section, we include a few tables and figures that clarify and elaborate upon various aspects of our experimental design and analysis. Figure A2 displays the endowment processes for the four different treatments as shown to subjects; Figure A3 plots the deviation of consumption and assets from the unconditionally optimal path by treatment and by sequence. Table A1 reports the RMSD of consumption from unconditional optimum by treatment and by sequence. Tables A2-A5 report on the robustness of the comparisons made across 17 alternative models using different sub-samples than the one reported on in the text. Finally, Table A6 shows the share of C-optimal types under alternative thresholds.

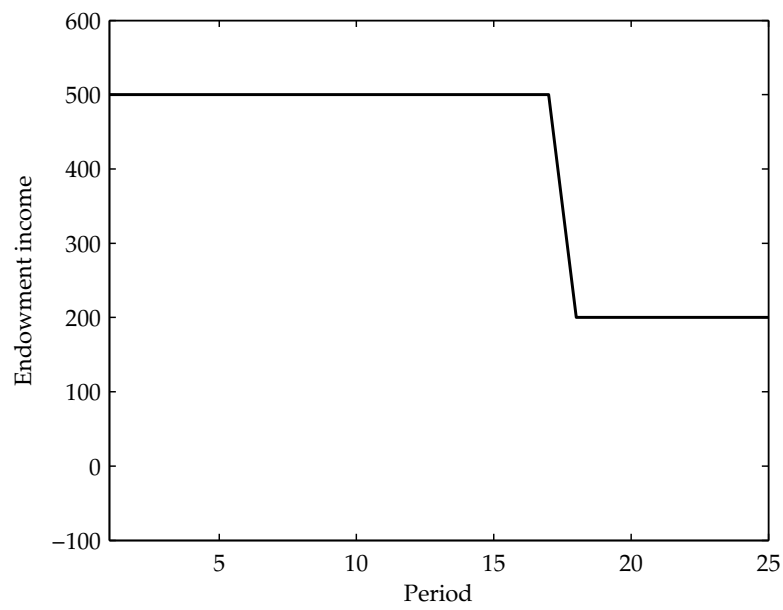

(a) $\mathrm{T} 1$

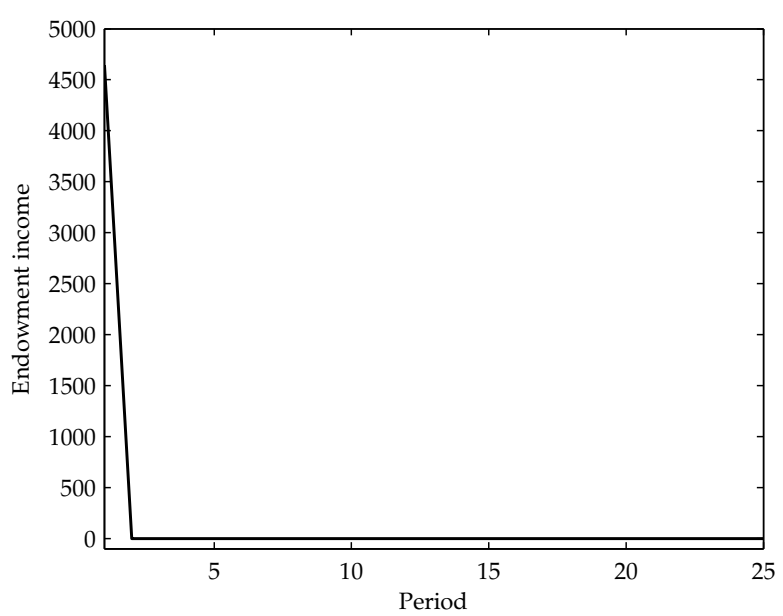

(c) $\mathrm{T} 3$

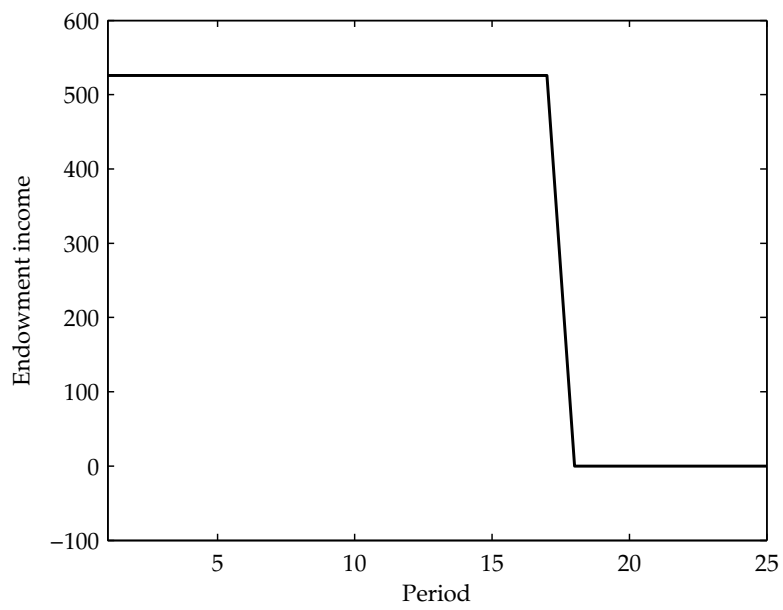

(b) $\mathrm{T} 2$

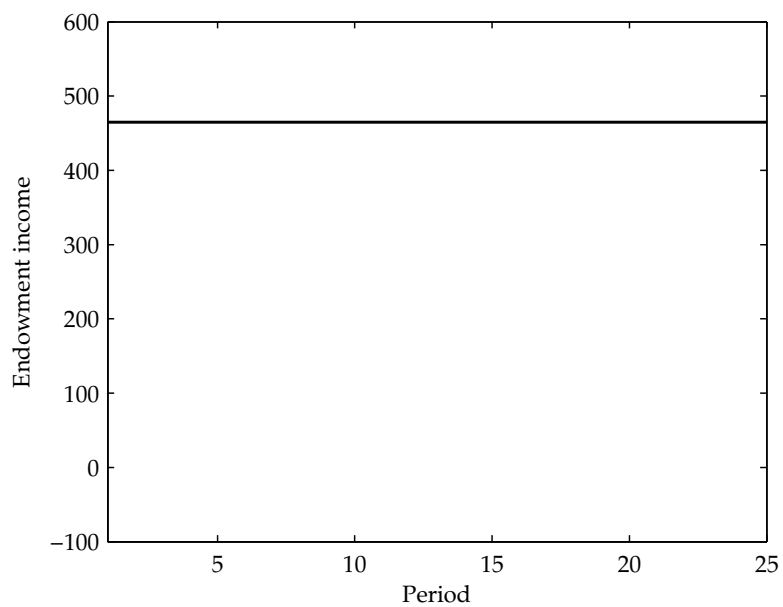

(d) $\mathrm{T} 4$

Figure A2: Endowment income by period 
Table A1: RMSD of consumption from the unconditional optimal path by treatment for each sequence

\begin{tabular}{lllll}
\hline \hline \multicolumn{2}{c}{$\begin{array}{l}\text { Mean } \\
(1)\end{array}$} & $\begin{array}{l}\text { T2 } \\
(2)\end{array}$ & $\begin{array}{l}\text { T3 } \\
(3)\end{array}$ & $\begin{array}{l}\text { T4 } \\
(4)\end{array}$ \\
\hline Panel A: S1 & & & \\
\hline T1 & 924.37 & $>^{*}$ & $>$ & $>^{* * *}$ \\
T2 & 890.90 & & $<$ & $>$ \\
T3 & 779.94 & & & $>^{* * *}$ \\
T4 & 871.03 & & & \\
\hline Panel B: S2 & & & \\
\hline T1 & 748.18 & $>$ & $>$ & $>^{* *}$ \\
T2 & 747.21 & & $>$ & $>$ \\
T3 & 702.37 & & & $<$ \\
T4 & 617.32 & & & \\
\hline Panel C: S3 & & & \\
\hline T1 & 677.27 & $>$ & $<* *$ & $<$ \\
T2 & 608.13 & & $<* *$ & $<$ \\
T3 & 852.39 & & & $>$ \\
T4 & 784.39 & & & \\
\hline Panel D: S4 & & & \\
\hline T1 & 675.03 & $<$ & $<$ & $>$ \\
T2 & 665.14 & & $>$ & $>$ \\
T3 & 632.12 & & & $>$ \\
T4 & 677.32 & & & $>$ \\
\hline \hline
\end{tabular}

Note: Column (1) reports the average value for each treatment. Columns (2)-(4) report the sign of the difference between treatments and its significance $\left({ }^{* * *}>0.01,{ }^{* *}>0.05,{ }^{*}>0.1\right)$ using a Wilcoxon rank-sum test. < indicates the sum of ranks (beginning at 1 for the smallest value) of the row treatment is smaller than that of the column treatment, and $>$ indicates the opposite. 

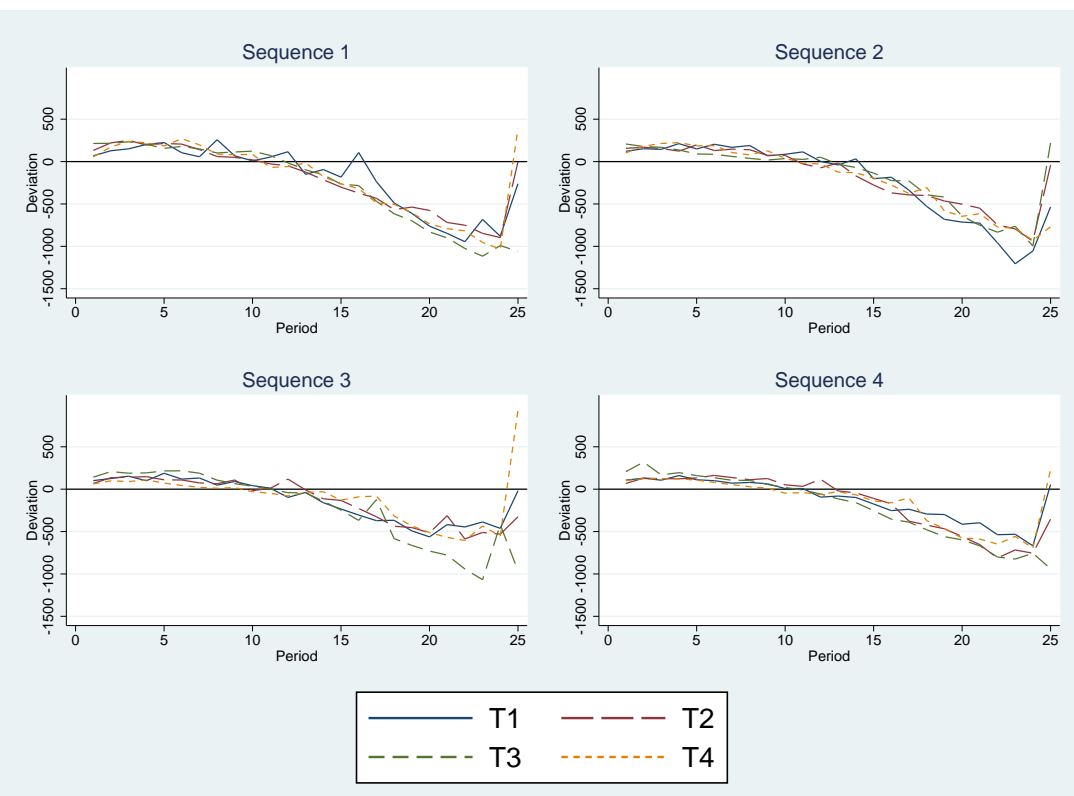

(a) Consumption

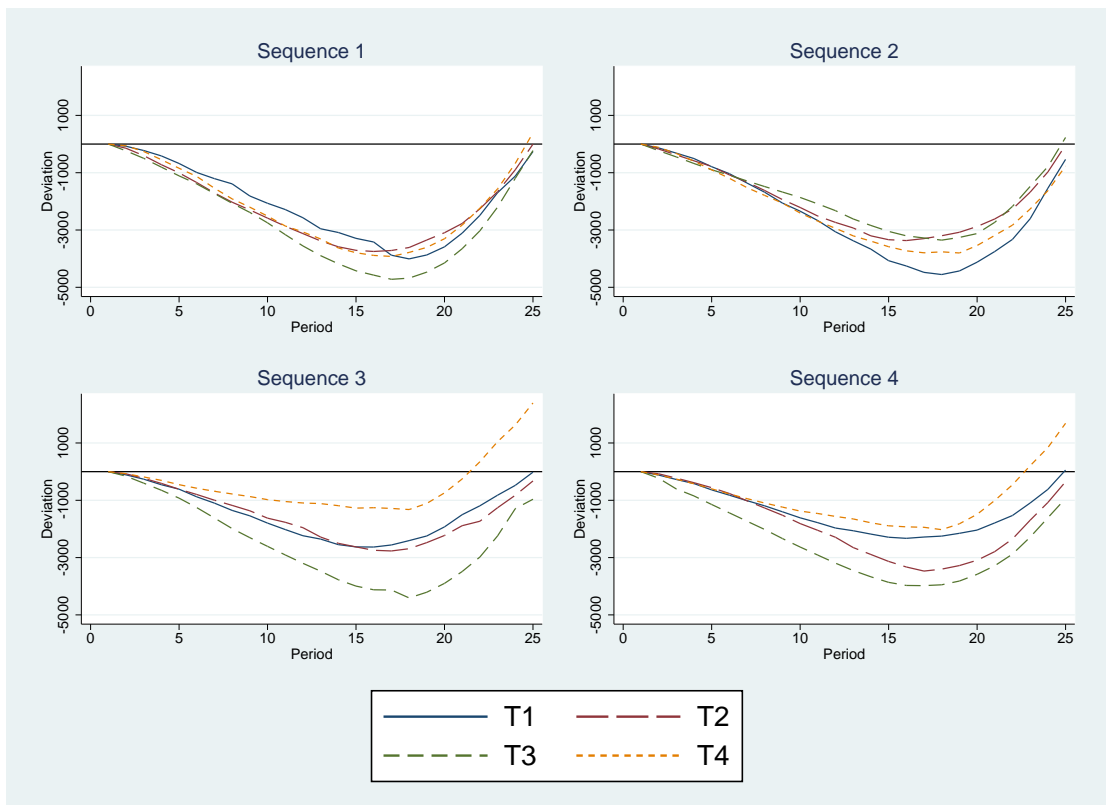

(b) Assets

Figure A3: Average deviation from the unconditionally optimal path by treatment and by sequence 


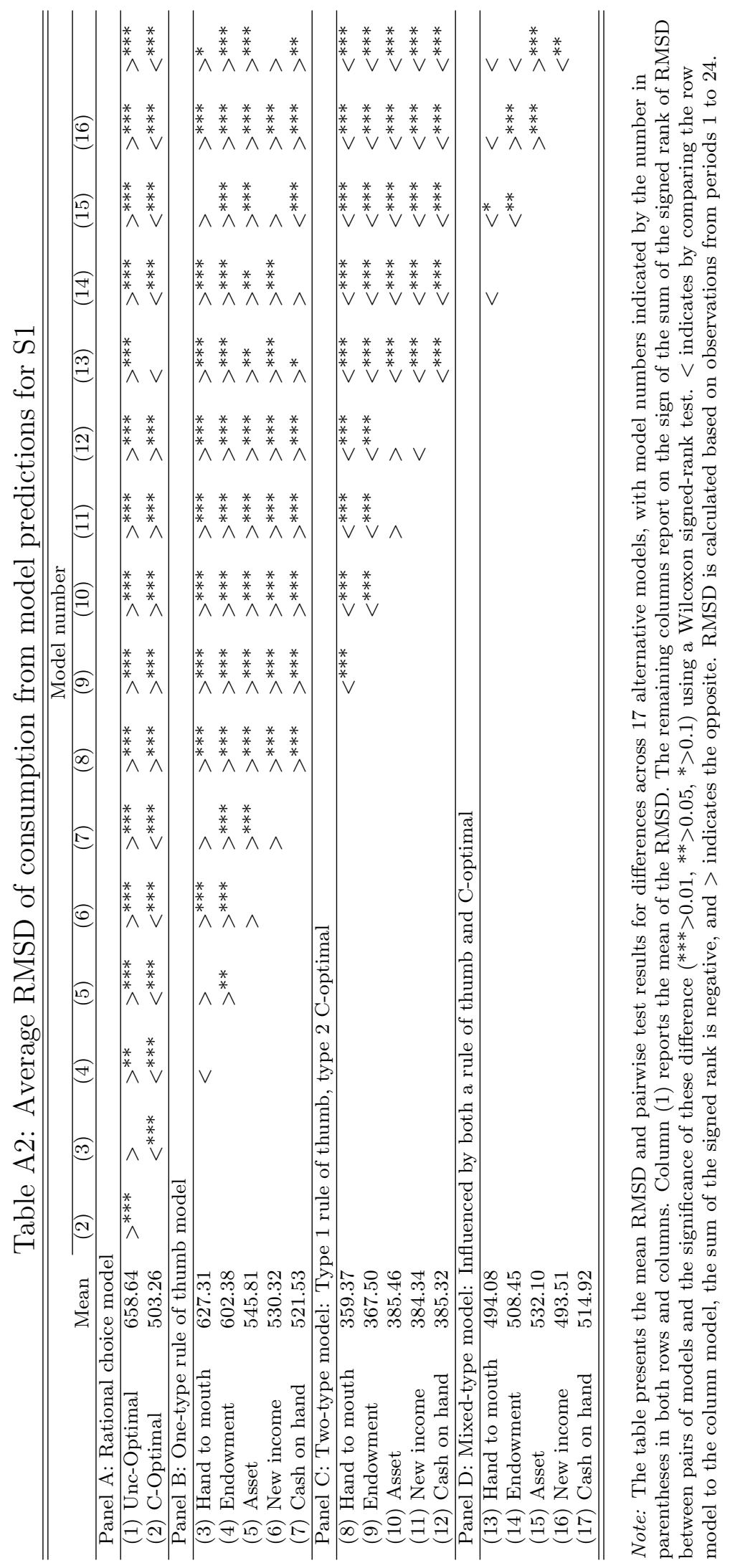




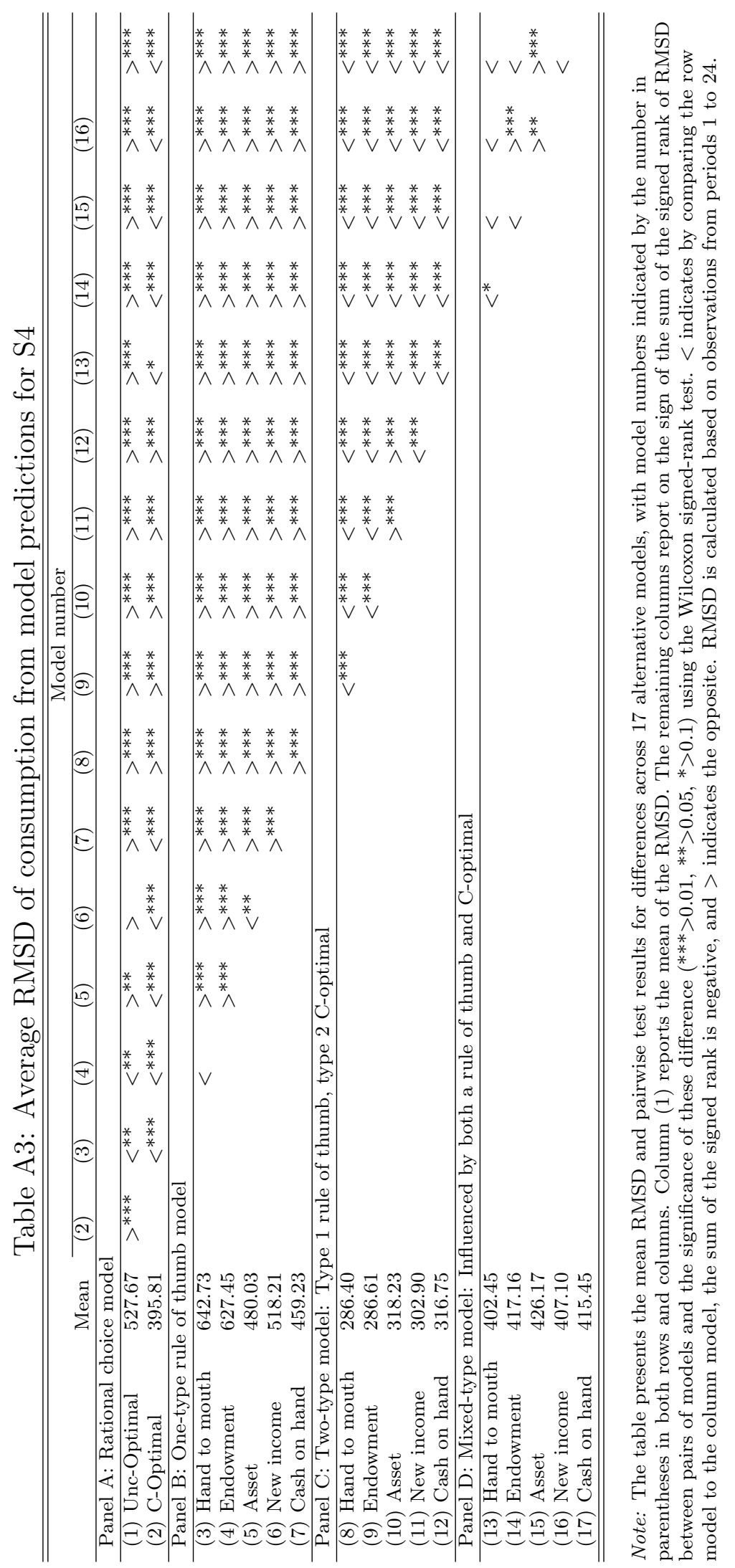




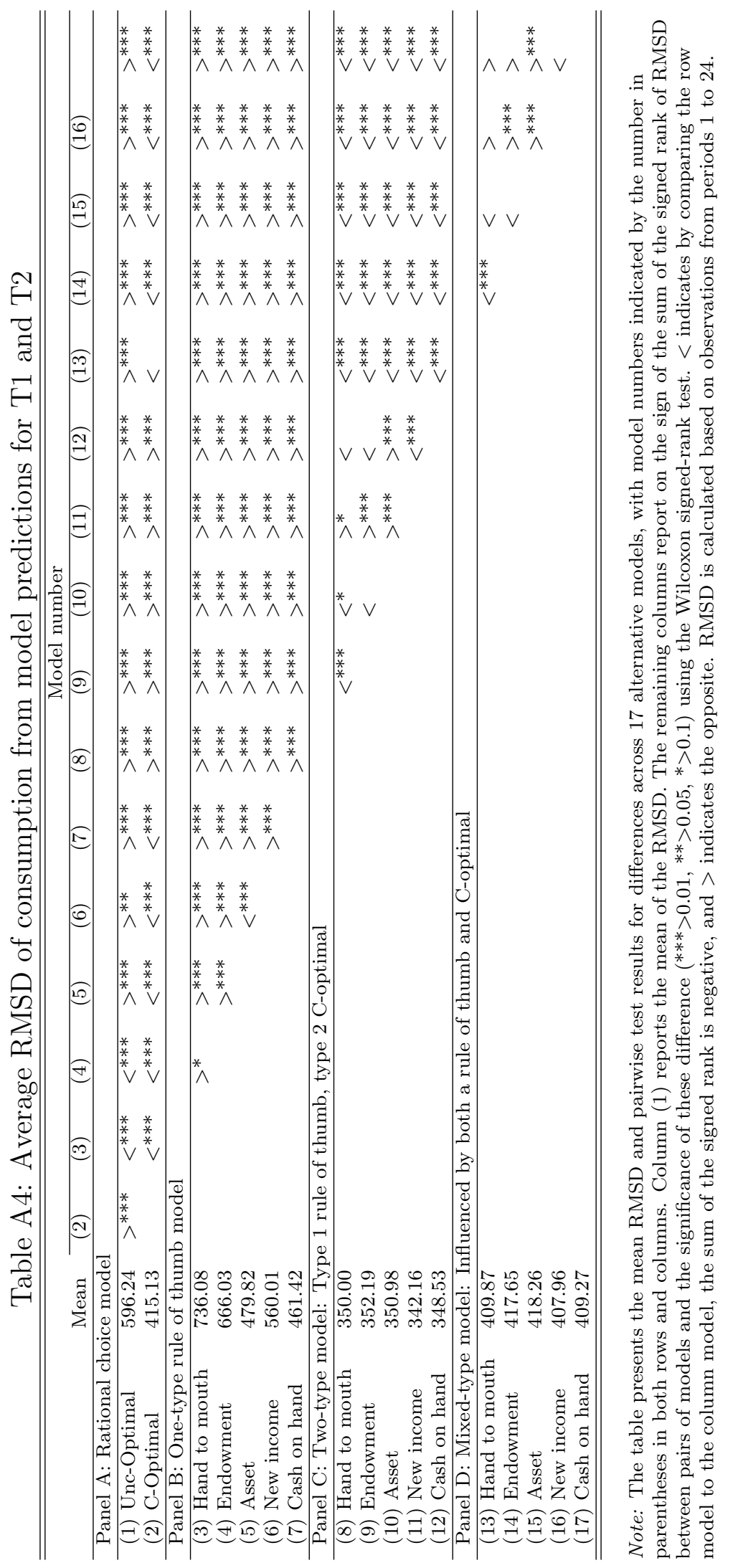




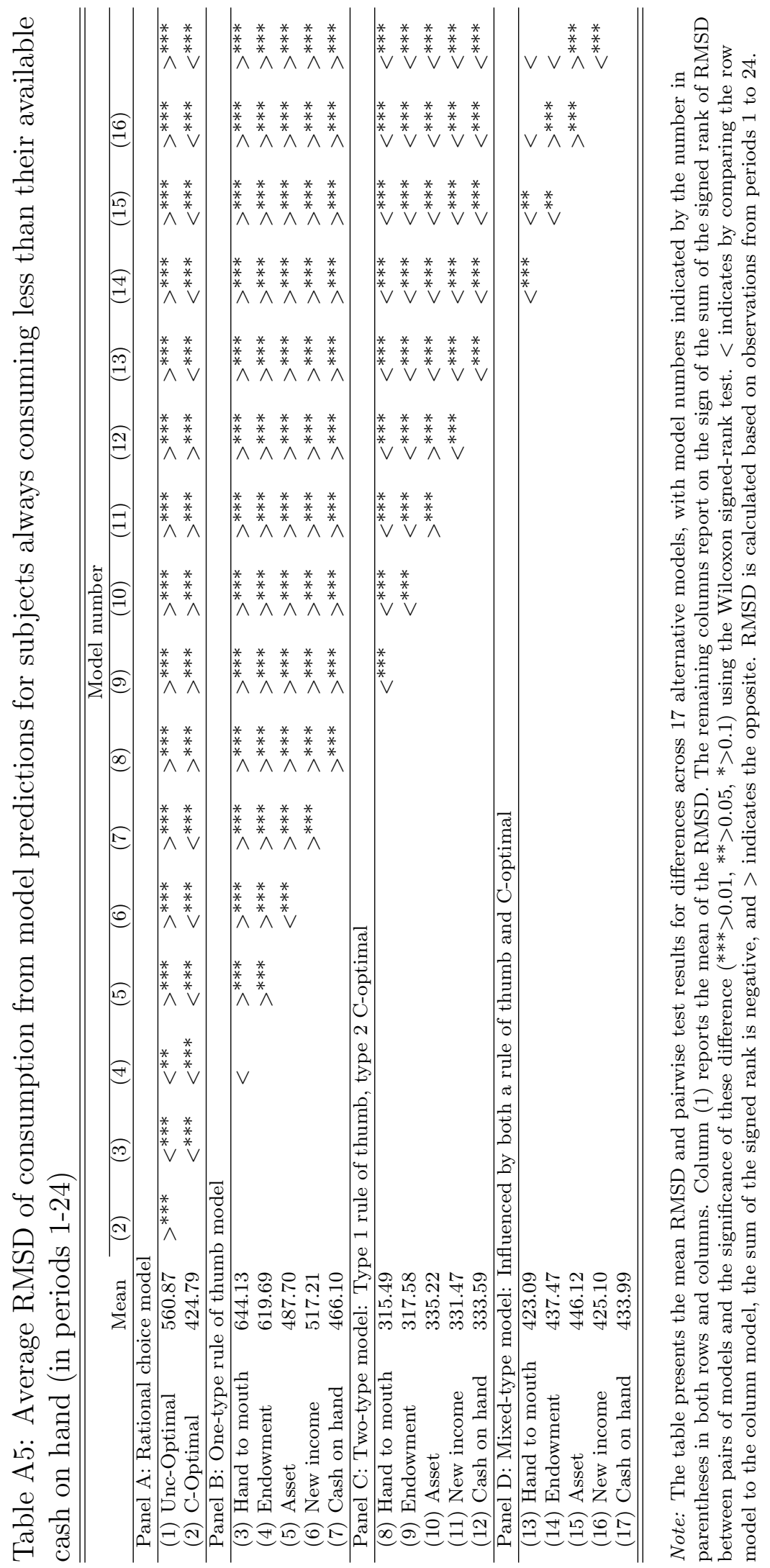


Table A6: Effect of treatments and sequences on the share of subjects behaving like Coptimal types under alternative thresholds for the RMSD of endowments in T4 and the conditionally optimal consumption path.

\begin{tabular}{|c|c|c|c|c|c|c|c|c|c|c|c|}
\hline & $\begin{array}{c}\text { Coef. } \\
\text { (1) }\end{array}$ & $\begin{array}{l}\text { S.E. } \\
(2)\end{array}$ & $\begin{array}{l}\text { T2 } \\
\text { (3) }\end{array}$ & $\begin{array}{l}\text { T3 } \\
\text { (4) }\end{array}$ & $\begin{array}{l}\text { T4 } \\
\text { (5) }\end{array}$ & & $\begin{array}{c}\text { Coef. } \\
\text { (1) }\end{array}$ & $\begin{array}{l}\text { S.E. } \\
(2)\end{array}$ & $\begin{array}{l}\mathrm{T} 2 \\
\text { (3) }\end{array}$ & $\begin{array}{l}\text { T3 } \\
\text { (4) }\end{array}$ & $\begin{array}{l}\mathrm{T} 4 \\
\text { (5) }\end{array}$ \\
\hline & \multicolumn{5}{|c|}{ Panel A: 100 percent } & \multicolumn{6}{|c|}{ Panel B: 95 percent } \\
\hline T1 & 0.17 & 0.05 & $>$ & $>^{*}$ & $<$ & T1 & 0.15 & 0.05 & $>^{*}$ & $>^{*}$ & $>^{*}$ \\
\hline $\mathrm{T} 2$ & 0.11 & 0.05 & & $>$ & $<* *$ & $\mathrm{~T} 2$ & 0.07 & 0.04 & & $>$ & $>$ \\
\hline T3 & 0.09 & 0.05 & & & $<* * *$ & T3 & 0.06 & 0.03 & & & $<$ \\
\hline $\mathrm{T} 4$ & 0.23 & 0.05 & & & & $\mathrm{~T} 4$ & 0.06 & 0.04 & & & \\
\hline S2 & 0.14 & 0.05 & & & & S2 & 0.13 & 0.04 & & & \\
\hline S3 & 0.14 & 0.05 & & & & S3 & 0.15 & 0.04 & & & \\
\hline S4 & 0.17 & 0.04 & & & & S4 & 0.15 & 0.04 & & & \\
\hline \multicolumn{6}{|c|}{ Panel C: 90 percent } & & \multicolumn{5}{|c|}{ Panel D: 85 percent } \\
\hline $\mathrm{T} 1$ & 0.12 & 0.04 & $>$ & $>^{*}$ & $>^{* *}$ & $\mathrm{~T} 1$ & 0.10 & 0.04 & $>$ & $>$ & $>^{* *}$ \\
\hline T2 & 0.08 & 0.04 & & $>$ & $>$ & T2 & 0.08 & 0.04 & & $>$ & $>^{*}$ \\
\hline T3 & 0.04 & 0.03 & & & $>$ & T3 & 0.04 & 0.03 & & & $>$ \\
\hline $\mathrm{T} 4$ & 0.02 & 0.04 & & & & $\mathrm{~T} 4$ & 0.01 & 0.04 & & & \\
\hline S2 & 0.10 & 0.03 & & & & S2 & 0.05 & 0.03 & & & \\
\hline S3 & 0.13 & 0.04 & & & & S3 & 0.09 & 0.04 & & & \\
\hline S4 & 0.14 & 0.04 & & & & $\mathrm{~S} 4$ & 0.13 & 0.04 & & & \\
\hline \multicolumn{6}{|c|}{ Panel E: 75 percent } & & & & & & \\
\hline $\mathrm{T} 1$ & 0.03 & 0.02 & $<^{*}$ & $>$ & $>^{* *}$ & & & & & & \\
\hline $\mathrm{T} 2$ & 0.07 & 0.03 & & $>^{*}$ & $>^{* * *}$ & & & & & & \\
\hline T3 & 0.02 & 0.02 & & & $>^{*}$ & & & & & & \\
\hline $\mathrm{T} 4$ & -0.02 & 0.02 & & & & & & & & & \\
\hline S2 & 0.03 & 0.02 & & & & & & & & & \\
\hline S3 & 0.05 & 0.02 & & & & & & & & & \\
\hline S4 & 0.06 & 0.03 & & & & & & & & & \\
\hline
\end{tabular}

Note: For each panel, Column (1) reports the coefficients and Column (2) reports the standard errors. Columns (3)-(5) report the sign of the difference in coefficients between treatments and statistical significance $\left({ }^{* * *}>0.01,{ }^{* *}>0.05,{ }^{*}>0.1\right)$ using a one-sided t-test. $<$ indicates the coefficient of the row treatment is less than that of the column treatment, and $>$ indicates the opposite. 